\title{
A Simplified Simulation Procedure and Analysis of a Photovoltaic Solar System Using a Single Diode Model
}

\author{
Robinson Ndegwa, Elijah Ayieta, Justus Simiyu, Nicodemus Odero \\ Department of Physics, University of Nairobi, Nairobi, Kenya \\ Email: ndegwarg@uonbi.ac.ke
}

How to cite this paper: Ndegwa, R., Ayieta, E., Simiyu, J. and Odero, N. (2020) A Simplified Simulation Procedure and Analysis of a Photovoltaic Solar System Using a Single Diode Model. Journal of Power and Energy Engineering, 8, 65-93.

https://doi.org/10.4236/jpee.2020.89006

Received: August 28, 2020

Accepted: September 26, 2020

Published: September 29, 2020

Copyright (c) 2020 by author(s) and Scientific Research Publishing Inc. This work is licensed under the Creative Commons Attribution International License (CC BY 4.0)

http://creativecommons.org/licenses/by/4.0/

\begin{abstract}
A single diode model for a photovoltaic solar module is the most ideal and quick way of analyzing the module characteristics before implementing them in a solar plant. Solar modules manufacturers provide information for three critical points that are essential in I-V, P-V or P-I curves. In this study, we propose four separate simulation procedures to estimate the five-model parameters of an analogous single diode equivalent circuit by utilizing three cardinal points of the photovoltaic module I-V curve, described from experimental data using a solar simulator and manufacturer's datasheet. The main objective is to extract and use the five unknown parameters of a single diode model to describe the photovoltaic system using I-V ad P-V plots under different environmental conditions. The most influential parameters that greatly alter the cardinal points defined at short circuit point (SCP), the maximum power point (MPP) and the open circuit point(OCP) are the ideality factor $(n)$ and the diode saturation current $\left(I_{o}\right)$. For a quick and fast convergence, we have determined the optimal ideality factor $\left(n_{o}\right)$ and optimal saturation current $\left(I_{\text {oopt }}\right)$ as the primary parameters by first assuming the optimal values of $R_{s h}, R_{s}$ and $I_{p h}$ at standard test conditions (STC). Further, we evaluated the effects of $I_{p h}, R_{s}$ and $R_{s h}$ on I-V and P-V curves by considering the values of $n$ below $n_{o}$. We have evaluated different iterative procedures of determining $R_{s h}$ and $R_{s}$ at open-circuit, short-circuit point and the maximum-power points. These procedures have been classified into four approaches that guarantees positive shunt and series resistance for $n \leq n_{o}$. These approaches have been categorized by deriving the saturation current as a dependent variable at each cardinal point with or without $R_{s}$ and $R_{s h}$ pair. The values obtained for the five parameters have been used to simulate the photovoltaic solar module characteristic curves with great precision at different air temperatures and irradiances, considering the effect of Nominal Operating Cell Temperature
\end{abstract}


(NOCT).

\section{Keywords}

Five-Parameter Model, Ideality Factor, Saturation Current, Series and Shunt Resistances

\section{Introduction}

Harvesting of renewable solar energy has grown rapidly over the past decade due to the availability of cheap and affordable modules and deep-cycle energy storage systems [1]. Although the installation of solar photovoltaic systems faces different challenges, the solar power has the highest potential in the world as a major source of clean energy [2] [3]. Some of these challenges include diverse environmental factors such as varying solar irradiance and temperatures, dust and shades, low solar cell efficiency and high installation costs [4]. These drawbacks have attracted numerous research works for tracking the optimum power generated by a photovoltaic module at various environmental conditions in order to improve its efficiency [5]-[10]. Photovoltaic systems should be optimized to work at the maximum power for any solar irradiation level and ambient temperature. Modeling and simulation of the photovoltaic systems gives a better understanding of the maximum power point using characteristic curves [11].

A single diode model of a solar system has been studied for decades since it offers an elaborate, simple and reliable analysis of the current-voltage characteristics of solar cells [12] [13] [14]. The model requires extremely thorough and careful computation of $I_{p h}, I_{o}, n, R_{s}$ and $R_{s h}$ parameters that are based on the equivalent circuit analysis using Schottky's diode equation [15].

Several techniques based on soft computing have been studied for unknown parameters determination using evolutionary algorithms [16]. These methods are strongly convergent and have less computing time. However, due to their stochastic nature, their efficiency depends on the choice of control parameters and search ranges which require high computational power [17] [18].

Analytical and numerical methods are the traditional techniques for estimating all parameters of a single diode photovoltaic model [19] [20]. The analytical approach relies heavily on the availability of data for short-circuit current $\left(I_{s c}\right)$, maximum power point voltage $\left(V_{m p p}\right)$, maximum power point current $\left(I_{m p p}\right)$, open-circuit voltage ( $\left.V_{o c}\right)$ and IV-curve intersection slopes [21] [22] [23]. Several authors have used information provided from the manufacturer's datasheets for $I_{s c}, V_{o c} I_{m p p}, V_{m p p}$ to determine the photovoltaic parameters using nonlinear least square (NLS) algorithm [24], normalized root mean-square deviation (NRMSD) [25] [26], Newton-Raphson algorithm [27] [28] and Lambert W Function [29] [30] [31] [32] [33]. These approaches offer quick, robust and faster ways of extracting the parameters of a single-diode photovoltaic model. The precision of these approaches is based primarily on the accuracy of the data pro- 
vided for the three crucial points on the I-V curve [20]. Standard photovoltaic module datasheet values for $I_{s c}, V_{o o} I_{m p p}$ and $V_{m p p}$ are approximated to one or two decimal places while $P_{\text {mpp }}$ values are given in the nearest tenth for all modules with the same power rating. However, each solar module has its individual values for each of these points at STC [34]. Therefore datasheet values can introduce significant errors in simulating the I-V or P-V curves. Numerical methods, on the contrary, are based on iterative algorithms for fitting simulated I-V curves into the experimental data [20] [35] [36]. This paper presents combined analytical and numerical approaches for determining the ideality factor $(n)$, diode saturation current $\left(I_{o}\right)$, photocurrent $\left(I_{p h}\right)$, series $\left(R_{s}\right)$ and shunt $\left(R_{s h}\right)$ resistances for a single diode photovoltaic model. The analytical approach gives a straightforward, simple and rapid way of extracting ideality factor and saturation current by approximating their optimum values using three critical points from either the data sheet and/or the experimental data. The numerical approach gives the precise values of the ideality factor and saturation current in the proximity of optimal ideality factor $\left(n_{o}\right)$ and optimal saturation current $\left(I_{o p t}\right)$ respectively. Further, series $\left(R_{s}\right)$ and shunt $\left(R_{s h}\right)$ resistances that are not provided in the manufacturer's datasheet are determined using iterative algorithms. Finally, the photo current is explicitly determined using the extracted $n, I_{o}, R_{s}, R_{s h}$ and datasheet or experimental values. A comparison of simulated I-V and P-V curves from datasheet and experimental data values is also presented for different environmental conditions.

\section{A Single Diode Model}

Figure 1 shows a single diode equivalent circuit that can be evaluated using Equation (1). A current source is connected in series to $R_{s}$ and in parallel to the Shockley's diode [37] and shunt resistor $R_{s h}$.

The equivalent circuit can be presented mathematically by

$$
I=I_{p h}-I_{o}\left(\exp \left(\frac{q\left(V+I R_{s}\right)}{n K T}\right)-1\right)-\frac{V+I R_{s}}{R_{s h}} .
$$

where; $T=298.15 \mathrm{~K}, q$ is the charge of an electron $=1.602176634 \times 10^{-19} \mathrm{C}$ and $k$ is the Boltzmann's Constant $=1.380649 \times 10^{-23} \mathrm{~m}^{2} \cdot \mathrm{s}^{-2} \cdot \mathrm{kg} \cdot \mathrm{K}^{-1}$.

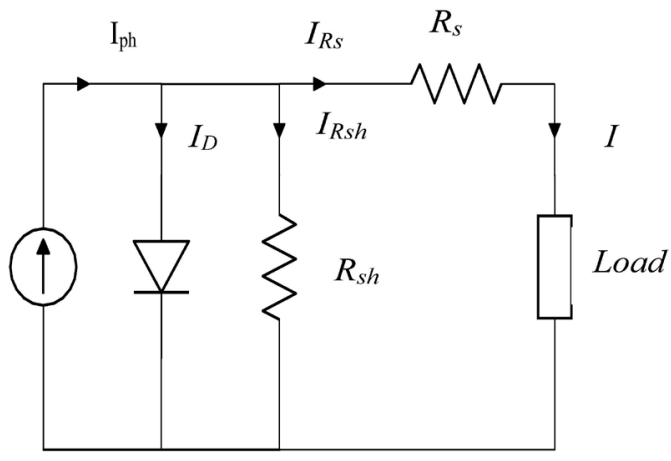

Figure 1. A single diode equivalent circuit. 


\section{Evaluation of a Single Diode Model at Three Critical Points in I-V and P-V Curves}

The critical points of I-V and P-V curves for a photovoltaic system are the short circuit (SC), the maximum power point (MPP) and open-circuit (OC). These points play an important role since a quick look at their values gives a clear picture of the photovoltaic module characteristic and performance. We can use Equation (1) and rearrange it at each point as follows:

1) At short circuit, $I=I_{s c}, V=0$;

We can rewrite Equation (1) as

$$
I_{s c}=I_{p h}-I_{o}\left(\exp \frac{I_{s c} R_{s}}{n N_{s} V_{t}}-1\right)-\frac{I_{s c} R_{s}}{R_{s h}} .
$$

or

$$
I_{p h}=I_{s c}+I_{o}\left(\exp \frac{I_{s c} R_{s}}{n N_{s} V_{t}}-1\right)+\frac{I_{s c} R_{s}}{R_{s h}} .
$$

where $V_{t}=k T / q=0.025692607$ is the thermal voltage.

2) At Open Circuit, $I=0, V=V_{o c}$

Equation (1) can be rearranged as

$$
I_{p h}=I_{o}\left(\exp \frac{V_{o c}}{n N_{s} V_{t}}-1\right)+\frac{V_{o c}}{R_{s h}} .
$$

3) At Maximum Power Point, $I=I_{m p p}, V=V_{m p p}$;

We can similarly replace $I=I_{m p p}, V=V_{m p p}$ in equation to obtain

$$
I_{m p p}=I_{p h}-I_{o}\left(\exp \frac{V_{m p p}+I_{m p p} R_{s}}{n N_{s} V_{t}}-1\right)-\frac{V_{m p p}+I_{m p p} R_{s}}{R_{s h}} .
$$

The above equations can be used to evaluate and determine the five unknown parameters using the experimental or manufacturer's data as discussed in the following sections.

\section{Determination of Unknown Parameters for a Single Diode Photovoltaic Model}

The transcendental Equation (1) has five unknown parameters that must be determined in order to have a model that represents the experimental data. These parameters include photocurrent $\left(I_{p h}\right)$, ideality factor $(n)$, saturation current $\left(I_{o}\right)$, series $\left(R_{s}\right)$ and shunt $\left(R_{s h}\right)$ resistances that can be derived using $I_{s o} I_{m p p}, V_{o c}$ and $V_{m p p}$.

The following sections 4.1 to 4.3 , addresses a detailed mathematical derivation of $I_{p h}, I_{o}$ and $n$ equations, outlining the disadvantages and benefits of each method. Section 4.4 discusses analytical approaches for $R_{s}$ and $R_{s h}$ determination.

\subsection{Photocurrent $\left(I_{p h}\right)$ Analysis}

The photocurrent $\left(I_{p h}\right)$ can be determined from Equations $((2),(3))$ or by re- 
writing Equation (5) as

$$
I_{p h}=I_{m p p}+I_{o}\left(\exp \frac{V_{m p p}+I_{m p p} R_{s}}{n N_{s} V_{t}}-1\right)+\frac{V_{m p p}+I_{m p p} R_{s}}{R_{s h}} .
$$

However, $I_{p h}$ depends on the solar irradiance and module surface temperature (T). Therefore, the relationship between $I_{p h}, T$ and actual irradiance $\left(s_{a}\right)$ can be deduced using temperature coefficient of short circuit current $\left(K_{I}\right)$ as discussed in [27] [38] [39]. Thus,

$$
I_{p h}=\frac{s_{a}}{S_{S T C}}\left[I_{p h_{S T C}}+K_{I}\left(T-T_{S T C}\right)\right] .
$$

\subsection{Saturation Current $\left(I_{o}\right)$}

The saturation current can be evaluated using Equation (1) at the three critical points by maintaining constant temperature at the standard test condition, where $T_{S T C}=25^{\circ} \mathrm{C}$.

\subsubsection{Saturation Current $\left(I_{o}\right)$ at Each Critical Point}

1) At the short circuit, Equation (2) can be rearranged to give

$$
I_{o}=\frac{I_{p h} R_{s h}-I_{s c} R_{s h}-I_{s c} R_{s}}{R_{s h}\left(\exp \left(\frac{I_{s c} R_{s}}{n N_{s} V_{t}}\right)-1\right)} .
$$

2) At maximum power point, Equation (5) can be reorganized to obtain

$$
I_{o}=\frac{I_{p h} R_{s h}-I_{m p p} R_{s h}-V_{m p p}-I_{m p p} R_{s}}{R_{s h}\left(\exp \left(\frac{V_{m p p}+I_{m p p} R_{s}}{n N_{s} V_{t}}\right)-1\right)} .
$$

Setting the boundary condition of $R_{s} \approx 0, R_{s h} \approx \infty$ and $I_{p h} \approx I_{s o}$ Equation (9) yields

$$
I_{o}=\frac{I_{s c}-I_{m p p}}{\exp \frac{V_{m p p}}{n N_{s} V_{t}}-1} .
$$

3) At the open circuit, Equation (4) can be rearranged to give

$$
I_{o}=\frac{I_{p h} R_{s h}-V_{o c}}{R_{s h}\left(\exp \left(\frac{V_{o c}}{n N_{s} V_{t}}\right)-1\right)} .
$$

Similarly, setting boundary condition of $R_{s h} \approx \infty$ and $I_{p h} \approx I_{s o}$ Equation (11) yields

$$
I_{o}=\frac{I_{s c}}{\exp \left(\frac{V_{o c}}{n N_{s} V_{t}}\right)-1} .
$$

\subsubsection{Saturation Current $\left(I_{o}\right)$ Calculation by Combining Two Out of Three Critical Point Equations}

The saturation current can also be calculated by combining two of either Equations ((3), (4) or (6)). Subtracting Equations ((3) and (4)) eliminates $I_{p h}$ as re- 
ported by [27] [40] and [41]. This reduces to

$$
\left[I_{o}\right]_{I_{s c}, V_{o c}}=\frac{I_{s c} R_{s h}+I_{s c} R_{s}-V_{o c}}{R_{s h}\left(\exp \left(\frac{V_{o c}}{n N_{s} V_{t}}\right)-\exp \left(\frac{I_{s c} R_{s}}{n N_{s} V_{t}}\right)\right)} .
$$

Once more, taking $R_{s} \approx 0$ and $R_{s h} \approx \infty$, we can rewrite Equation (13) as

$$
\left[I_{o_{o p t}}\right]_{I_{s c}, V_{o c}}=\frac{I_{s c}}{\exp \left(\frac{V_{o c}}{n N_{s} V_{t}}\right)} .
$$

Similarly, Equation (3) can be merged with Equation (6) at $I_{s c}$ and $P_{m p p}$ to obtain

$$
\left[I_{o}\right]_{I_{s c}, P_{m p p}}=\frac{V_{m p p}+I_{m p p} R_{s h}+I_{m p p} R_{s}-I_{s c} R_{s}-I_{s c} R_{s h}}{R_{s h}\left(\exp \left(\frac{I_{s c} R_{s}}{n N_{s} V_{t}}\right)-\exp \left(\frac{V_{m p p}+I_{m p p} R_{s}}{n N_{s} V_{t}}\right)\right)} .
$$

Returning to $R_{s} \approx 0$ and $R_{s h} \approx \infty$, Equation (15) reduces to

$$
\left[I_{o_{o p t}}\right]_{I_{s c}, P_{m p p}}=\frac{I_{s c}-I_{m p p}}{\exp \left(\frac{V_{m p p}}{n N_{s} V_{t}}\right)} .
$$

Finally, considering Equations ((4) and (6)) at $V_{o c}$ and $P_{m p p}$, we can deduce the saturation current as

$$
\left[I_{o}\right]_{V_{o c}, P_{m p p}}=\frac{V_{m p p}-V_{o c}+I_{m p p} R_{s h}+I_{m p p} R_{s}}{R_{s h}\left(\exp \left(\frac{V_{o c}}{n N_{s} V_{t}}\right)-\exp \left(\frac{V_{m p p}+I_{m p p} R_{s}}{n N_{s} V_{t}}\right)\right)} .
$$

Again, assuming $R_{s} \approx 0$ and $R_{s h} \approx \infty$, we can rewrite Equation (17) as

$$
\left[I_{o_{o p t}}\right]_{V_{o c}, P_{m p p}}=\frac{I_{m p p}}{\exp \left(\frac{V_{o c}}{n N_{s} V_{t}}\right)-\exp \left(\frac{V_{m p p}}{n N_{s} V_{t}}\right)} .
$$

\subsubsection{Dependence of the Saturation Current on Temperature}

The dark saturation current has been reported to be independent of irradiance and has been regarded as the reverse saturation current which is the reverse current in a solar cell caused by diffusion of minority carriers from the neutral regions to the depletion region in the absence of irradiation [42] [43]. However, the dark saturation current strongly depends on the parameters of the temperature, the cross-sectional area of semiconductor and the concentration of the intrinsic carrier [43] [44]. The intrinsic carrier concentration number also depends on the state conduction and valence band densities and the semiconductor energy band-gap $\left(E_{g}\right)$ [44]. Therefore, as discussed by [45] [46], saturation current density can be derived as

$$
J_{o}=q A N_{V} N_{C}\left[\frac{1}{N_{A}} \sqrt{\frac{D_{n-}}{\tau_{n-}}}+\frac{1}{N_{D}} \sqrt{\frac{D_{p^{+}}}{\tau_{p+}}}\right] \exp \left(\frac{-E_{g}}{k T}\right) .
$$


where $N_{b}$ is the effective density of states in the valence band, $N_{C}$ is the effective density of states in the conduction band, $N_{A}$ is acceptor impurities concentration, $N_{D}$ is donor impurities concentration, $\tau_{n-}$ is electron (minority carrier) lifetime, $\tau_{p+}$ is hole (minority carrier) lifetime, A is cross-sectional area of solar cell, $E_{g}$ is the energy band-gap, $D_{n-}$ is electron diffusion coefficient and $D_{p+}$ is hole diffusion coefficient.

Applying Equation (1) to a solar module as explained by [47], we can obtain

$$
I_{o}=I_{o_{S T C}}\left[\frac{T}{T_{S T C}}\right]^{3} \exp \frac{-q E_{g}}{n N_{s}}\left(\frac{1}{T_{S T C}}-\frac{1}{T}\right) .
$$

The saturation current can be calculated using Equations (8) to (18) at constant temperature of $25^{\circ} \mathrm{C}$ to obtain $I_{O_{S T C}}$. This requires careful analysis of these equations to determine the one that produces the best results in the replication of the experimental data. However, these equations depend on $I_{p h}, R_{s}, R_{s h}$ and $n$, which are unknown parameters that must be determined first.

\subsection{Ideality Factor $(n)$}

The ideality factor can be evaluated as a function of series ad shunt resistances or by considering their extreme values. Considering the approach we introduced in our previous work [48], in which the ideality factor was evaluated in the optimum ideality-factor neighborhood, in this paper we discuss further extraction of $n$ for $0 \leq n \leq n_{o}$.

\subsubsection{Ideality Factor ( $n$ ) Dependence on $\boldsymbol{R}_{s}$ and $\boldsymbol{R}_{s h}$}

The exponential term $\exp \left(I_{s c} R_{s} / n N_{s} V_{t}\right)$, in the denominators of Equations ((13) and (15)) can be omitted, as it has insignificant value compared to the other exponential terms in the respective denominators. Therefore, Equations ((13) and (15)) can be written as

$$
I_{o}=\frac{I_{s c} R_{s h}+I_{s c} R_{s}-V_{o c}}{R_{s h} \exp \left(\frac{V_{o c}}{n N_{s} V_{t}}\right)} .
$$

and

$$
I_{o}=\frac{I_{s c} R_{s}+I_{s c} R_{s h}-V_{m p p}-I_{m p p} R_{s h}-I_{m p p} R_{s}}{R_{s h} \exp \left(\frac{V_{m p p}+I_{m p p} R_{s}}{n N_{s} V_{t}}\right)} .
$$

Equating Equations ((21) and (22)) and solving for $n$ gives

$$
n=\frac{V_{o c}-V_{m p p}-I_{m p p} R_{s}}{N_{s} V_{t}\left[\ln \left(\frac{I_{s c} R_{s h}+I_{s c} R_{s}-V_{o c}}{I_{s c} R_{s h}+I_{s c} R_{s}-I_{m p p} R_{s h}-I_{m p p} R_{s}-V_{m p p}}\right)\right]} .
$$

4.3.2. Ideality Factor ( $n$ ) Dependence on Extremum Values of $\boldsymbol{R}_{s}$ and $\boldsymbol{R}_{s h}$ The ideality factor can also be derived simply by first removing the exponential terms using logarithm and subtracting Equations (4) and (5) to obtain 


$$
n=\frac{V_{s} V_{t}\left[\ln \left(\frac{I_{p h}+I_{o}-\frac{V_{o c}}{R_{s h}}}{\left.I_{p h}+I_{o}-I_{m p p}-\frac{V_{m p p}+I_{m p p} R_{s}}{R_{s h}}\right)}\right)\right]}{.}
$$

In Equation (24) the ideality factor relates with $I_{p h}, I_{o}, R_{s}$ and $R_{s h}$ at both maximum power point $\left(I_{m p p}, V_{m p p}\right)$ and open circuit point $\left(V_{o c}\right)$. For initial estimates, the $R_{s}$ and $R_{s h}$ values can be ignored in both the numerator and denominator. They have very small and very large values, where $R_{s} \approx 0$ and $R_{s h} \approx \infty$, respectively. This makes it possible to introduce the short circuit point into Equation (24) since the photocurrent relationship given in Equation (3) reduces to $I_{p h}$ $\approx I_{s c}$. Therefore, the ideality factor can be evaluated with respect to saturation current and the three crucial points as

$$
n=\frac{V_{o c}-V_{m p p}}{N_{s} V_{t}\left[\ln \left(\frac{I_{s c}+I_{o}}{I_{s c}+I_{o}-I_{m p p}}\right)\right]} .
$$

This assumption gives $n_{o}$ in terms of $I_{s o} I_{m p p}, V_{o c}$ and $V_{m p p}$ only. Hence,

$$
n_{o}=\frac{V_{o c}-V_{m p p}}{N_{s} V_{t}\left[\ln \left(\frac{I_{s c}}{I_{s c}-I_{m p p}}\right)\right]} \text {. }
$$

\subsection{Shunt Resistance $\left(R_{s h}\right)$ and Series Resistance $\left(R_{s}\right)$}

The values of shunt and series resistance can be evaluated using the equations derived using $I_{s c}, I_{m p p}, V_{m p p}$ and $V_{o c}$ through an iterative process. Using $I_{m p p}$ and $V_{\text {mpp }}$ the relationship between $R_{s h}$ and $R_{s}$ can be evaluated by rearranging Equation (5) to obtain

$$
R_{s h}=\frac{V_{m p p}+I_{m p p} R_{s}}{I_{p h}-I_{m p p}-I_{o}\left(\exp \left(\frac{V_{m p p}+I_{m p p} R_{s}}{n N_{s} V_{t}}\right)-1\right)} .
$$

The combination of Equations (3) and (4) gives a relation between $R_{s h}$ and $R_{s}$ in terms of $I_{s c}$ and $V_{o c}$ given by

$$
R_{s h}=\frac{V_{o c}-I_{s c} R_{s}}{I_{s c}+I_{o} \exp \left(\frac{I_{s c} R_{s}}{n N_{s} V_{t}}\right)-I_{o} \exp \left(\frac{V_{o c}}{n N_{s} V_{t}}\right)} .
$$

Similarly, the combination of Equations ((3) and (5)) gives a relation between $R_{s h}$ and $R_{s}$ in terms of $I_{s c} I_{m p p}$ and $V_{m p p}$ to obtain

$$
R_{s h}=\frac{V_{m p p}+I_{m p p} R_{s}-I_{s c} R_{s}}{I_{s c}-I_{m p p}-I_{o} \exp \left(\frac{V_{m p p}+I_{m p p} R_{s}}{n N_{s} V_{t}}\right)+I_{o} \exp \left(\frac{I_{s c} R_{s}}{n N_{s} V_{t}}\right)} .
$$

Again, merging Equations ((4) and (5)) yields 


$$
R_{s h}=\frac{V_{o c}-V_{m p p}-I_{m p p} R_{s}}{I_{m p p}+I_{o} \exp \left(\frac{V_{m p p}+I_{m p p} R_{s}}{n N_{s} V_{t}}\right)-I_{o} \exp \left(\frac{V_{o c}}{n N_{s} V_{t}}\right)} .
$$

Shunt resistance $\left(R_{s h}\right)$ and series resistance $\left(R_{s}\right)$ can also be analyzed using the vanishing slope of the output power at maximum power point of Equation (1) and derivatives at short circuit and open circuit points with respect to $V$ [12] [27] [49] [50] [51].

The derivative of Equation (1) with respect to $V$ gives

$$
\frac{\partial I}{\partial V}=-\frac{I_{o}}{n N_{s} V_{t}}\left\{\left(1+\frac{\partial I}{\partial V} R_{s}\right) \exp \left(\frac{V+I R_{s}}{n N_{s} V_{t}}\right)\right\}-\frac{1}{R_{s h}}\left(1+\frac{\partial I}{\partial V} R_{s}\right) .
$$

The derivative at short circuit point gives

$$
\left[\frac{\partial I}{\partial V}\right]_{I=I_{s c}}=-\frac{1}{R_{s h}} .
$$

and at open circuit point

$$
\left[\frac{\partial I}{\partial V}\right]_{V=V_{o c}}=-\frac{1}{R_{s}} .
$$

At maximum power point the power derivative with respect to voltage can be evaluated as

$$
\left[\frac{\partial P}{\partial V}\right]=\left(\frac{\partial I}{\partial V}\right) V+I=0 .
$$

At maximum power point the power derivative with respect to voltage can be evaluated as

$$
-\frac{I_{m p p}}{V_{m p p}}=-\frac{I_{o}}{n N_{s} V_{t}}\left\{\left(1-\frac{I_{m p p}}{V_{m p p}} R_{s}\right) \exp \left(\frac{V_{m p p}+I_{m p p} R_{s}}{n N_{s} V_{t}}\right)\right\}-\frac{1}{R_{s h}}\left(1+\frac{I_{m p p}}{V_{m p p}} R_{s}\right) .
$$

By rearranging Equation (35) we can obtain

$$
R_{s h}=\frac{V_{m p p}-I_{m p p} R_{s}}{I_{m p p}-\frac{I_{o}}{n N_{s} V_{t}}\left(V_{m p p}+I_{m p p} R_{s}\right) \exp \left(\frac{V_{m p p}+I_{m p p} R_{s}}{n N_{s} V_{t}}\right)} .
$$

\subsubsection{Evaluation and Analysis of $\boldsymbol{R}_{s h}$ and $\boldsymbol{R}_{S}$ Pairs}

This paper presents a simplified analytical approach for evaluating and analyzing $R_{s h}$ and $R_{s}$ pairs. Considering Equations ((27)-(30) and (36)), there are only three unknown parameters, i.e., $R_{s}$, the ideality factor and saturation current that appears on the right hand side of each equation. The saturation current has been derived in Equations ((14), (16) and (18)) with respect to ideality factor. A simple mathematical analysis can be done by replacing $I_{o}$ in Equations ((27)-(30) and (36)) using Equation (14) to remain with ideality factor as the only unknown parameter. Comparing Equations ((27)-(30) and (36)), only Equation (30) that gives positive values of $R_{s h}$ and $R_{s}$ pairs after replacing $I_{o}$ with Equation (14). Therefore, eliminating $I_{o}$ of Equation (30) using (14) gives 


$$
R_{s h}=\frac{V_{o c}-V_{m p p}-I_{m p p} R_{s}}{I_{m p p}-I_{s c}+I_{s c} \exp \left(\frac{V_{m p p}+I_{m p p} R_{s}-V_{o c}}{n N_{s} V_{t}}\right)} .
$$

Equation (37) can be analyzed using an iterative approach to obtain the $\left[R_{s}\right.$, $R_{s h}$ ] pairs by selecting the values of $n$ that are less than $n_{o}$. As introduced by [52], the $R_{s}$ and $R_{s h}$ limits can be calculated using

$$
R_{s h_{\max }}=\frac{V_{o c}-V_{m p p}}{I_{m p p}} .
$$

and

$$
R_{s h_{\min }}=\frac{V_{m p p}}{I_{s c}-I_{m p p}}-R_{s_{\text {max }}} .
$$

Limiting the ideality factor selection within the $0 \leq n \leq n_{o}$ range and setting $R_{s}$ and $R_{s h}$ limits given by Equations ((38) and (39)) respectively, makes the process fast and robust. In addition, the ideality factor is selected in order to get an $R_{s}$ and $R_{s h}$ pair that guarantees the simulated maximum power $\left(P_{m p p}(\operatorname{sim})\right)$ matches maximum power obtained experimentally, where $P_{m p p}(\exp t)=I_{m p p} * V_{m p p}$. The $P_{m p p}(\operatorname{sim})$ relationship can be derived by replacing $I=I_{m p p}$ and $V=V_{m p p}$ in Equation (1) to yield

$P_{m p p}(\operatorname{sim})=V_{m p p}\left(I_{p h}-I_{o}\left(\exp \frac{V_{m p p}+I_{m p p} R_{s}}{n N_{s} V_{t}}-1\right)-\frac{V_{m p p}+I_{m p p} R_{s}}{R_{s h}}\right)=P_{m p p}(\exp t)$.

The value of $I_{p h}$ in Equation (40) can be replaced using Equation (3) by letting the term $I_{o} \exp \left(I_{s c} R_{s} / n N_{s} V_{t}\right) \approx 0$, since it has insignificant value compared to the other terms. Thus we can rewrite,

$$
I_{p h}=I_{s c}+\frac{I_{s c} R_{s}}{R_{s h}} .
$$

Further, the saturation current in Equation (40) can be replaced by Equation (16) to obtain

$$
\begin{aligned}
& P_{m p p}(\operatorname{sim}) \\
= & V_{m p p}\left(\left(I_{s c}+\frac{I_{s c} R_{s}}{R_{s h}}\right)-\left(\frac{I_{s c}-I_{m p p}}{\exp \left(\frac{V_{m p p}}{n N_{s} V_{t}}\right)}\right)\left(\exp \frac{V_{m p p}+I_{m p p} R_{s}}{n N_{s} V_{t}}-1\right)-\frac{V_{m p p}+I_{m p p} R_{s}}{R_{s h}}\right) \\
= & P_{m p p}(\text { expt })
\end{aligned}
$$

Both Equations (37) and (42) can be solved simultaneous by arbitrarily selecting ideality factor below $n_{o}$ and by increasing the values of $R_{s}$ from zero to $R_{s_{\max }}$ using computer software. This process is repeated until the value of simulated maximum power $\left(P_{m p p}(\operatorname{sim})\right)$ matches maximum power obtained experimentally $P_{\text {mpp }}($ expt $)$ or has an error margin of less than $0.5 \%$ [53].

The percentage error in power can be expressed as 


$$
P_{m p p} \text { Error }=\Delta P_{m p p} \%=\frac{P_{m p p}-I_{m p p} R_{s}}{I_{m p p} V_{m p p}} .
$$

\subsubsection{Extraction of Ideality Factor $n, R_{s}$ and $\boldsymbol{R}_{s h}$ Using an Iterative Computational Process}

The values of $n, R_{s}$ and $R_{s h}$ can be extracted using an iterative process using Equation (37) and verified using both Equations ((42) and (43)). The ideality factor is arbitrarily chosen starting from $n \leq n_{0}$ [52] in steps of -0.001 and applied in Equation (37) to obtain $\left[R_{s}, R_{s h}\right]$ pair. Subsequently, in the iterative stage, these $n, R_{s}$, and $R_{s h}$ values are used in Equation (42) until the trio that satisfies $P_{m p p}(\operatorname{sim}) \equiv P_{m p p}($ expt $)$ is achieved.

\subsubsection{Simulation of $\boldsymbol{R}_{s h}$ and $\boldsymbol{R}_{S}$ Pairs}

Table 1 provides a summary of data from the KC200GT datasheet profile and experimental data for Solinc $120 \mathrm{~W}$ measured using Gsola XJCM-10A solar simulator that has been used to simulate $R_{s h}$ and $R_{s}$ pairs. Figure 2 illustrates the $R_{s h}$ and $R_{s}$ relationship given by Equation (37) and has been sketched using data presented in Table 1.

The optimum ideality factors and optimum saturation current are also listed in Table 1. The optimum ideality factors values have been determined using Equation (26). Similarly, the optimal saturation current has been determined using Equation (14). These optimal values set the limit for both ideality factor and saturation current but they do not give the best results when plotting the I-V and $\mathrm{P}-\mathrm{V}$ curves. This leads to further analysis of ideality factors near the optimal values and their respective saturation current.

Table 2 gives a summary of ideality factor $n, R_{s}, R_{s h}, I_{o}$ and $I_{p h}$ parameters for Solinc $120 \mathrm{~W}$ and Kyocera KC200GT solar modules. The main aim has been to use the available information for $I_{s \mathcal{O}} I_{m p p}, V_{o c}$ and $V_{m p p}$ to arrive at most appropriate values listed in Table 2 . These values have been used as the starting figures for I-V relationship as demonstrated in the following section.

\section{Improved Analysis of Current-Voltage Relationship for Five-Parameter Model Using Newton-Raphson Technique}

The previous sections have demonstrated a simplified approach of obtaining the Table 1. Solinc $120 \mathrm{~W}$ and Kyocera KC200GT photovoltaic modules data at STC.

\begin{tabular}{ccc}
\hline Parameters & Solinc $120 \mathrm{~W}$ & KC200GT \\
\hline$I_{m p p}(\mathrm{~A})$ & 7.1814 & 7.61 \\
$V_{\text {mpp }}(\mathrm{V})$ & 16.905 & 26.3 \\
$I_{s c}(\mathrm{~A})$ & 7.59995 & 8.21 \\
$V_{o c}(\mathrm{~V})$ & 21.529 & 32.9 \\
$N_{s}$ & 36 & 54 \\
$n_{o}$ & 1.72529 & 1.81928 \\
$I_{o-\text { opt }}(\mathrm{A})$ & $1.0439 \mathrm{E}-05$ & $1.7807 \mathrm{E}-5$ \\
\hline
\end{tabular}




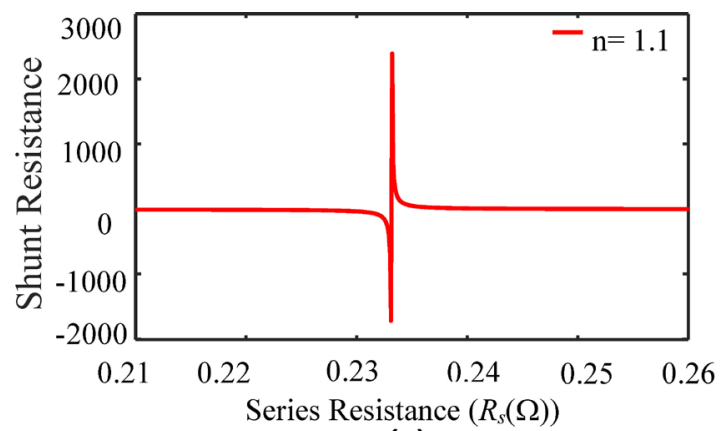

(a)

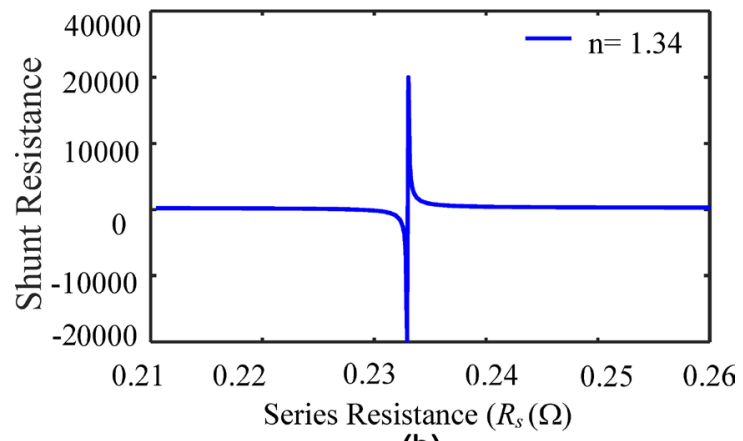

(b)

Figure 2. A graph of $R_{s h}$ versus $R_{s}$ at STC for (a) Solinc $120 \mathrm{~W}$ from solar simulator values and (b) for KC200GT from datasheet values.

Table 2. Extracted parameters for Solinc $120 \mathrm{~W}$ and Kyocera KC200GT photovoltaic modules using equations (37) and (42).

\begin{tabular}{ccc}
\hline Parameters & Solinc $120 \mathrm{~W}$ & KC200GT \\
\hline$n$ & 1.1 & 1.34 \\
$R_{s}(\Omega)$ & 0.236 & 0.214 \\
$R_{s h}(\Omega)$ & 3746.809 & 525.145 \\
$I_{o}(\mathrm{~A})$ & $4.9089 \mathrm{E}-09$ & $1.6936 \mathrm{E}-07$ \\
$I_{p h}(\mathrm{~A})$ & 7.59995 & 8.2297
\end{tabular}

model parameters. The approach heavily depended on the values of $I_{s c} I_{m p p}, V_{o c}$ and $V_{m p p}$; the main cardinal points. This can be considered as a rough understanding of the solution of Equation (1). We have thus applied Newton-Raphson technique to iteratively solve Equation (1) in order to consider all points in characterization of photovoltaic modules using I-V and P-V curves. The Newton-Raphson technique is based on estimation of a given function $f(I)=0$ [54].

We can rearrange Equation (1) as,

$$
f(I)=I_{p h}-I_{o}\left[\exp \left(\frac{V+I R_{s}}{n N_{s} V_{t}}\right)-1\right]-\frac{V+I R_{s}}{R_{s h}}-I=0 .
$$

Differentiating Equation (44) with. respect to $I$ leads to

$$
\frac{\partial(f(I))}{\partial I}=-\frac{I_{o} R_{s}}{n N_{s} V_{t}}\left[\exp \left(\frac{V+I R_{s}}{n N_{s} V_{t}}\right)\right]-\frac{R_{s}}{R_{s h}}-1 .
$$


Therefore, we can apply Equations (44) and (45) to implement the Newton-Raphson approach and obtain

$$
I_{j+1}=I_{j}-\frac{f\left(I_{j}\right)}{\frac{\partial\left(f\left(I_{j}\right)\right)}{\partial I}}=I_{j}-\frac{I_{p h}-I_{o}\left[\exp \left(\frac{V+I_{j} R_{s}}{n N_{s} V_{t}}\right)-1\right]-\frac{V+I_{j} R_{s}}{R_{s h}}-I_{j}}{-\frac{I_{o} R_{s}}{n N_{s} V_{t}}\left[\exp \left(\frac{V+I_{j} R_{s}}{n N_{s} V_{t}}\right)\right]-\frac{R_{s}}{R_{s h}}-1}
$$

where, $j$ represents the number of iterative process.

Equations (44)-(46) require initial values of $\mathrm{n}$ and $\mathrm{R}_{\mathrm{s}}$. In this paper, we introduce the new approach presented in section 4.4 that easily determines the trio values of $n, R_{s}$ and $R_{s h}$. These values are also used to calculate $I_{o}$ and $I_{p h}$. Implementation of all five parameter values in Equations (44)-(46) reduces the number of iterative processes needed to obtain the most suitable I and $\mathrm{V}$ values, thereby increasing the computation speed.

The identified values of $\mathrm{I}$ and $\mathrm{V}$ are applied in the power equation given by

$$
P=I_{p h} V-I_{o} V\left[\exp \left(\frac{V+I R_{s}}{n N_{s} V_{t}}\right)-1\right]-\frac{V^{2}}{R_{s h}}-V I \frac{R_{s}}{R_{s h}} .
$$

\subsection{Analysis of Different Approaches for Extracting Five-Model Parameters}

All the five parameters in Table 2 for Solinc $120 \mathrm{~W}$ and KC200GT modules that have been deduced using the new simplified simulation procedure are applied in solving Equation (46) to obtain a good approximation of the output current. This approach offers a simple and very efficient calculation procedure for all current and voltage values starting from $I=0$ to $I=I_{s c}$ and $V=0$ to $V=V_{o c}$ It offers very precise solutions for all the points needed to plot the I-V and P-V or P-I curves.

In this work, we have classified four most suitable data extraction approaches for determining I and V using Newton-Raphson method. These categories depend on the choice of saturation current equations discussed in section 4.2 and 4.3.1. Category 1 is based on saturation currents that are dependent on $R_{s}$ and $R_{s h}$ resistances at open and short circuit points (SCDR-OS) where $I_{o}$ is calculated using Equations ((11), (13) and (21)). Category 2 is based on saturation current that is independent of $R_{s}$ and $R_{s h}$ resistances at open and short circuit points (SCIR-OS), where $I_{o}$ is calculated using Equations ((12) and (14)). Categories 3 and 4 are based on saturation currents at both open circuit and maximum power points that are dependent on $R_{s}$ and $R_{s h}$ resistances (SCDR-OMP) and saturation currents that are independent of $R_{s}$ and $R_{s h}$ resistances (SCIR-OMP), where the $I_{o} \mathrm{~s}$ are calculated using Equations ((17) and (18)) respectively. The use of saturation current defined by Equations ((9), (10), (15), (16) and (22)) does, however, provide unsatisfactory data for I and V.

These procedures can be implemented using the algorithm shown in Figure 4 which outlines all the steps required to retrieve the data for plotting the I-V and 
$\mathrm{P}-\mathrm{V}$ curves as follows.

- The process starts with input values of $I_{s o}, I_{m p p}, V_{m p p}, V_{o o}, N_{s}$ and $V_{t}$ from Table 1.

- Followed by setting the number of iterations, NiMax for current approximation and NvMax for voltage resolution plus precision description for $R_{s}$ increment defined by Rsinc.

- The algorithm presented in Figure 3 is then applied to obtain $n, R_{s}$ and $R_{s h}$ values.

- These $n, R_{s}$ and $R_{s h}$ are used to calculate $I_{o}$ and $I_{p h}$ for the first iteration of determining the current and voltage data.

- The process is repeated severally for each iteration with an increment of $R_{s}$ $\left(R_{s}=R_{s}+R \operatorname{sinc}\right)$ until NiMax and NvMax are reached by solving Equations (44)-(46).

- The P-error is then evaluated to determine the most suitable values for $n, R_{s}$, $R_{s h}, I_{o}$ and $I_{p h}$ which give the best current, voltage and power data.

- If the error in power is greater than $0.5 \%$, the process is repeated by inputting a new value of ideality actor.

- Finally, the process ends by plotting I-V and P-V curves and the cardinal point markers if the error in power is less or equal to $0.5 \%$.

\subsection{Evaluation of Extracted Parameters for Solinc $120 \mathrm{~W}$ and KC200GT Modules Using the Four Approaches}

Table 3 \& Table 4 display the five-model parameter data for Solinc $120 \mathrm{~W}$ and

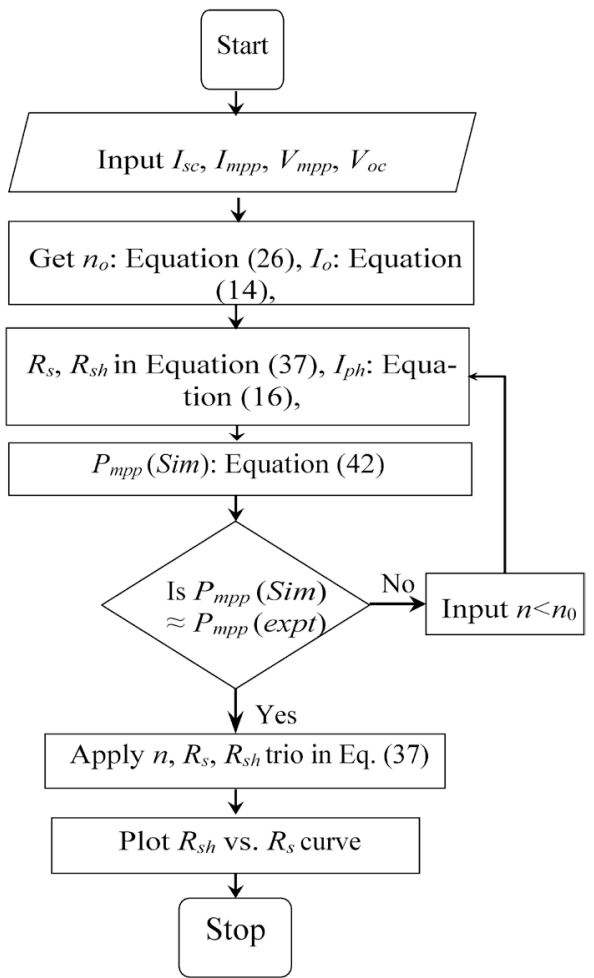

Figure 3. An algorithm for evaluating the $n, R_{s}$ and $R_{s h}$ using $I_{s c} I_{m p p}, V_{m p p}$ and $V_{o c}$ 
Table 3. Simulated data for Solinc 120, where $I_{o}$ has been calculated using approach 1 of Equations ((11), (13) or (21)), approach 2 of Equations ((12) or (14)), approach 3 Equation (17) and approach 4 Equation (18).

\begin{tabular}{|c|c|c|c|c|c|c|c|c|}
\hline Parameters & $\begin{array}{l}\text { Equations for } \\
\left\{R_{s}, R_{s h}\right\} \text { pair }\end{array}$ & $\begin{array}{c}\text { Series } \\
\text { Resistance } \\
\left(R_{s}(\Omega)\right)\end{array}$ & $\begin{array}{c}\text { Shunt } \\
\text { Resistance } \\
\left(R_{s h}(\Omega)\right)\end{array}$ & $\begin{array}{c}\text { Ideality } \\
\text { Factor ( } n)\end{array}$ & $\begin{array}{c}\text { Saturation } \\
\text { Current } \\
\left(I_{o} \times 10^{-9}(\mathrm{~A})\right)\end{array}$ & $\begin{array}{l}\text { Photo Current } \\
\qquad\left(I_{p h}(\mathrm{~A})\right)\end{array}$ & $\begin{array}{c}\text { Power } \\
\left(P_{m p p}(\mathrm{~W})\right)\end{array}$ & $\begin{array}{c}\text { Change in } \\
\text { Power } \\
\left(\Delta P_{m p p} \%\right)\end{array}$ \\
\hline \multirow[t]{2}{*}{ Approach 1} & (27) & 0.233 & 6694.87 & 1.1 & 4.8984 & 7.6014 & 121.463 & 0.0456 \\
\hline & (29) & 0.233 & 6943.00 & 1.1 & 4.8857 & 7.6032 & 121.505 & 0.0844 \\
\hline \multirow[t]{5}{*}{ Approach 2} & (27) & 0.233 & 3746.81 & 1.1 & 4.9089 & 7.6045 & 121.457 & 0.0444 \\
\hline & (28) & 0.233 & $706,150,048$ & 1.1 & 4.9089 & 7.6000 & 121.464 & 0.0503 \\
\hline & (29) & 0.233 & $37,898.74$ & 1.1 & 4.9089 & 7.6003 & 121.462 & 0.0486 \\
\hline & $(30)$ & 0.233 & -6653.75 & 1.1 & 4.9089 & 7.6443 & 122.190 & 0.6481 \\
\hline & $(36)$ & 0.255 & -279.34 & 1.1 & 4.9089 & 7.6485 & 122.056 & 0.5380 \\
\hline \multirow[t]{4}{*}{ Approach 3} & $(27)$ & 0.233 & 3054.06 & 1.1 & 4.9009 & 7.6049 & 121.458 & 0.0452 \\
\hline & (28) & 0.233 & 240.07 & 1.1 & 4.8557 & 7.6443 & 121.026 & -0.3105 \\
\hline & (29) & 0.233 & $23,248.547$ & 1.1 & 4.9056 & 7.6008 & 121.469 & 0.0548 \\
\hline & $(36)$ & 0.254 & $12,008.21$ & 1.1 & 4.9036 & 7.6483 & 121.082 & -0.2642 \\
\hline \multirow[t]{4}{*}{ Approach 4} & (27) & 0.2395 & $18,565.30$ & 1.1 & 4.6883 & 7.6005 & 121.459 & 0.0280 \\
\hline & $(28)$ & 0.1501 & 59.71 & 1.1 & 4.6883 & 7.6286 & 121.319 & -0.0416 \\
\hline & (29) & 0.2395 & $34,945.22$ & 1.1 & 4.6883 & 7.6000 & 121.459 & 0.0283 \\
\hline & (36) & 0.2608 & 6726.41 & 1.1 & 4.6883 & 7.6496 & 121.062 & -0.1704 \\
\hline
\end{tabular}

Table 4. Simulated data for KC200GT, where Io has been calculated using approach 1 of equations (11), (13) or (21), approach 2 of equations (12) or (14), approach 3 Equation (17) and approach 4 Equation (18).

\begin{tabular}{|c|c|c|c|c|c|c|c|c|}
\hline Parameters & $\begin{array}{l}\text { Equations for } \\
\left\{R_{s}, R_{s h}\right\} \text { pair }\end{array}$ & $\begin{array}{c}\text { Series } \\
\text { Resistance } \\
\left(R_{s}(\Omega)\right)\end{array}$ & $\begin{array}{c}\text { Shunt } \\
\text { Resistance } \\
\left(R_{s h}(\Omega)\right)\end{array}$ & $\begin{array}{l}\text { Ideality } \\
\text { Factor }(n)\end{array}$ & $\begin{array}{c}\text { Saturation } \\
\text { Current }\left(I_{o} \times\right. \\
\left.10^{-7}(\mathrm{~A})\right)\end{array}$ & $\begin{array}{l}\text { Photo Current } \\
\qquad\left(I_{p h}(\mathrm{~A})\right)\end{array}$ & $\begin{array}{c}\text { Power }\left(P_{m p p}\right. \\
(\mathrm{W}))\end{array}$ & $\begin{array}{c}\text { Change in } \\
\text { Power } \\
\left(\Delta P_{m p p} \%\right)\end{array}$ \\
\hline \multirow[t]{2}{*}{ Approach 1} & (27) & 0.2187 & 712.83 & 1.34 & 1.6671 & 8.2174 & 200.143 & 0.000018 \\
\hline & (29) & 0.2187 & 904.25 & 1.34 & 1.6755 & 8.2151 & 200.218 & 0.0377 \\
\hline \multirow[t]{5}{*}{ Approach 2} & (27) & 0.2134 & 367.85 & 1.34 & 1.6936 & 8.2508 & 200.143 & 0.000015 \\
\hline & $(28)$ & 0.2134 & $71,669,727$ & 1.34 & 1.6936 & 8.2100 & 201.013 & 0.4345 \\
\hline & (29) & 0.2134 & 744.51 & 1.34 & 1.6936 & 8.2124 & 200.144 & 0.00051 \\
\hline & (30) & 0.2283 & $13,153.36$ & 1.34 & 1.6936 & 8.2100 & 200.076 & -0.0335 \\
\hline & (36) & 0.2165 & 1013.88 & 1.34 & 1.6936 & 8.2120 & 200.200 & 0.0283 \\
\hline \multirow[t]{4}{*}{ Approach 3} & (27) & 0.2161 & 749.58 & 1.34 & 1.6840 & 8.2152 & 200.143 & 0.000016 \\
\hline & $(28)$ & 0.2161 & 200.48 & 1.34 & 1.6616 & 8.2513 & 198.701 & -0.72038 \\
\hline & (29) & 0.2282 & $1,367,493$ & 1.34 & 1.6932 & 8.2107 & 200.152 & 0.0045 \\
\hline & (36) & 0.2198 & 379.03 & 1.34 & 1.6637 & 8.252 & 200.108 & -0.0176 \\
\hline \multirow[t]{4}{*}{ Approach 4} & (27) & 0.2258 & 368.61 & 1.34 & 1.6163 & 8.2531 & 200.143 & 0.000007 \\
\hline & (28) & 0.1002 & 85.55 & 1.34 & 1.6163 & 8.2196 & 199.970 & -0.0862 \\
\hline & (29) & 0.2279 & 934.82 & 1.34 & 1.6163 & 8.2120 & 200.143 & 0.000014 \\
\hline & $(36)$ & 0.2289 & 1068.57 & 1.34 & 1.6163 & 8.212 & 200.176 & 0.0165 \\
\hline
\end{tabular}


KC200GT solar modules and their simulated output power and errors. The following sections discuss the most realistic results of the five-model parameter that provide more practical data for each approach that fits experimental results. Four approaches are listed here since they give small percentage error.

\section{Approach 1}

The data shown in Table 3 \& Table 4 in rows 2 - 3 summarizes the Solinc $120 \mathrm{~W}$ and KC200GT parameters that have been extracted from the first category of data procedure. These data are based on open and short circuit points, where $I_{o}$ is determined using Equations ((11), (13) or (21)). However, this category only gives a satisfying $\left[R_{s}, R_{s h}\right]$ pair from Equations ((27) and (29)).

\section{Approach 2}

The data shown in Table 3 \& Table 4 in rows 4 - 8, give category 2 data for Solinc $120 \mathrm{~W}$ and KC200GT where $I_{o}$ has been calculated using either Equations (12) or (14) that are independent of $R_{s}, R_{s h}$ pair. This category gives satisfactory

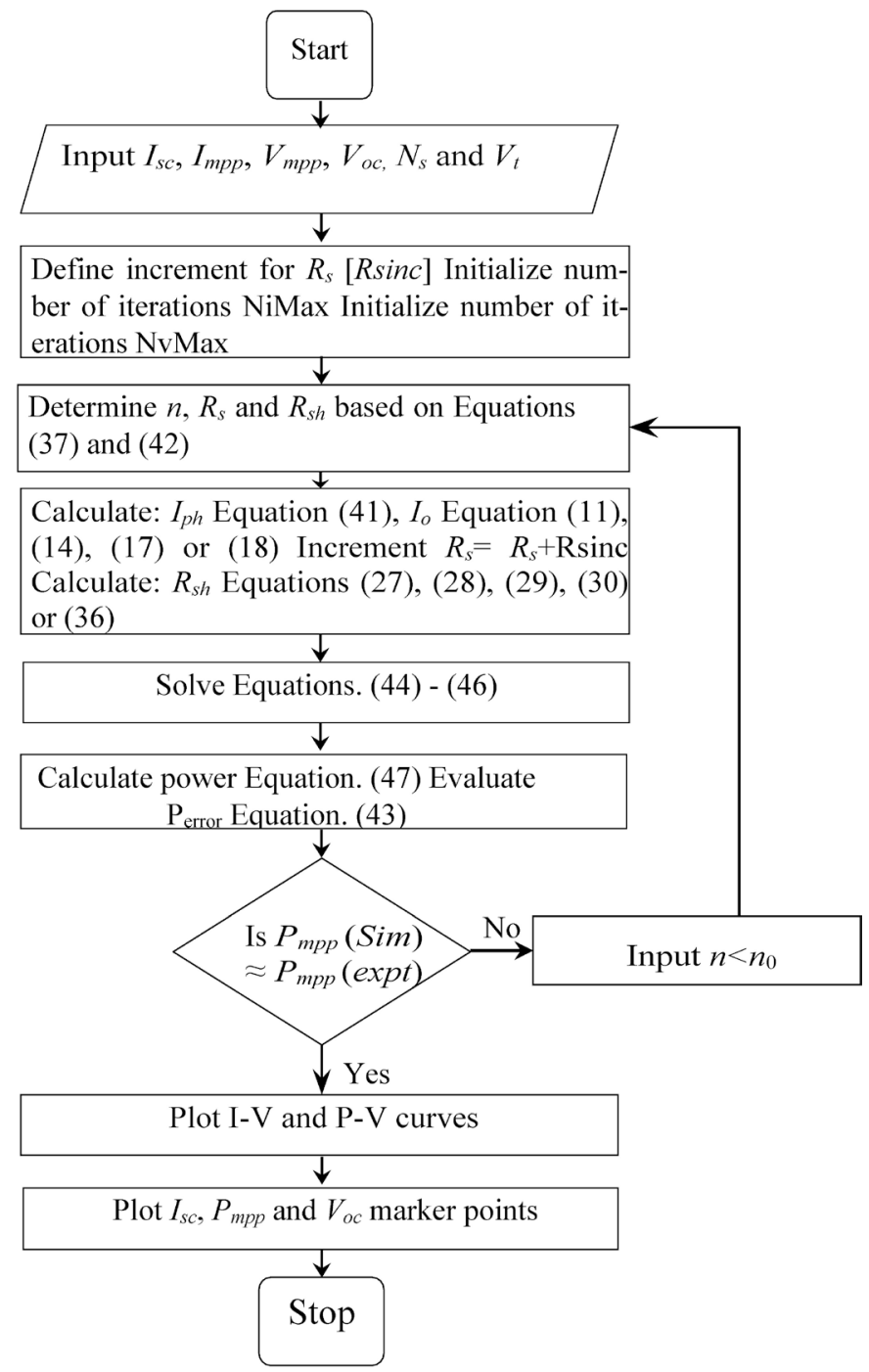

Figure 4. An algorithm for calculating current (I) using Newton-Raphson technique and plotting I-V and P-V curves. 
$\left[R_{s}, R_{s h}\right]$ pair from Equations ((27), (28) (29), (30) and (36)).

\section{Approach 3}

Again, the data shown in Table $3 \&$ Table 4 in rows 9 -12, represent category 3 where $I_{o}$ is determined using Equation (17). This category gives satisfactory $\left[R_{s}, R_{s h}\right]$ pair only from Equations ((27), (28), (29) and (36)).

\section{Approach 4}

Finally, rows 13 - 16 of Table 3 \& Table 4 give category 4 data for Solinc 120 $\mathrm{W}$ and KC200GT, where $I_{o}$ is determined using Equation (18) that is independent of $R_{s}, R_{s h}$ pair. This category also gives satisfactory $\left[R_{s}, R_{s h}\right]$ pair only from Equations ((27), (28), (29) and (36)).

It is clear from Table $3 \&$ Table 4 that the saturation current $\left(I_{o}\right)$ calculated using Equations ((12) or (14)) in approach 2 gives acceptable $\Delta P_{m p p}$ errors when applied to all $R_{s h}$ Equations ((27)-(30), or (36)).

Approach 1 gives satisfactory data when applied in Equations ((27) and (29)). Other approaches, 3 and 4 give reasonable results when applied in Equations ((27), (28), (29) and (36)). Evidently, Equations ((27) and (29)) that have been derived at maximum power point and combination of maximum power point and short circuit equations, respectively, give the best results of $\Delta P_{m p p}$ error for all saturation current equations at constant ideality factor. Equation (28) gives very large and very small values of $R_{s h}$ when applied in approaches 2 and 4 . All the four approaches give satisfactory data when compared with other methods reported by different authors as demonstrated in Table $5 \&$ Table 6 .

These data are summarized in Table 5 for $R_{s h}$ of Equation (27) that gives the smallest error for each approach. Approach 1 data and data from [52] have similar results while approaches 2 and 3 have different $R_{s h}$ values for the same $R_{s}=$ $0.233 \Omega$. However, approach 4 has $R_{s}=0.2395 \Omega$ that gives the least $\Delta P_{\text {mpp }}$ error and very large value of $R_{s h}=18,565 \Omega$. Analytical approach reported by [41] provides satisfactory parameters that are closer to the values obtained using the four approaches.

The values of five-model parameters obtained using approaches discussed in the works of [41] [52] have been compared with the values of parameters for

Table 5. Comparison of calculated parameters with other approaches in literature for Solinc $120 \mathrm{~W}$

\begin{tabular}{cccccc}
\hline Parameters & $\begin{array}{c}\text { Series } \\
\text { Resistance } \\
\left(R_{s}(\Omega)\right)\end{array}$ & $\begin{array}{c}\text { Shunt } \\
\text { Resistance } \\
\left(R_{s h}(\Omega)\right)\end{array}$ & $\begin{array}{c}\text { Ideality Factor } \\
(n)\end{array}$ & $\begin{array}{c}\text { Saturation } \\
\text { Current }\left(I_{o} \times\right. \\
\left.10^{-9}(\mathrm{~A})\right)\end{array}$ & $\begin{array}{c}\text { Photo Current } \\
\left(I_{p h}(\mathrm{~A})\right)\end{array}$ \\
\hline Approach 1 & 0.233 & 6694.87 & 1.1 & 4.5915 & 7.6014 \\
Approach 2 & 0.233 & 3746.81 & 1.1 & 4.9089 & 7.6045 \\
Approach 3 & 0.233 & 3054.06 & 1.1 & 4.9009 & 7.6049 \\
Approach 4 & 0.2395 & $18,565.30$ & 1.1 & 4.6883 & 7.6005 \\
[52] approach & 0.233 & 6694.87 & 1.1 & 4.8984 & 7.6014 \\
[41] approach & 0.264 & $16,400.11$ & 1.1 & 4.5915 & 7.6502 \\
\hline
\end{tabular}


Table 6. Comparison of calculated parameters with other approaches in literature for KC200GT.

\begin{tabular}{cccccc}
\hline Parameters & $\begin{array}{c}\text { Series } \\
\text { Resistance } \\
\left(R_{s}(\Omega)\right)\end{array}$ & $\begin{array}{c}\text { Shunt } \\
\text { Resistance } \\
\left(R_{s h}(\Omega)\right)\end{array}$ & $\begin{array}{c}\text { Ideality Factor } \\
(\boldsymbol{n})\end{array}$ & $\begin{array}{c}\text { Saturation } \\
\text { Current } \\
\left(I_{o}(\mathrm{~A})\right)\end{array}$ & $\begin{array}{c}\text { Photo Current } \\
\left(I_{p h}(\mathrm{~A})\right)\end{array}$ \\
\hline Approach 1 & 0.2187 & 712.83 & 1.34 & $1.667 \mathrm{E}-07$ & 8.2174 \\
Approach 2 & 0.2134 & 367.85 & 1.34 & $1.694 \mathrm{E}-07$ & 8.2508 \\
Approach 3 & 0.2161 & 749.58 & 1.34 & $1.684 \mathrm{E}-07$ & 8.2152 \\
Approach 4 & 0.2258 & 368.61 & 1.34 & $1.616 \mathrm{E}-07$ & 8.2531 \\
Data by [40] & 0.217 & 951.927 & 1.34 & $1.7100 \mathrm{E}-7$ & 8.212 \\
Data by [52] & 0.221 & 415.405 & 1.3 & $9.825 \mathrm{E}-8$ & 8.214 \\
Data by [50] & 0.231 & 594.851 & 1.3 & $9.6990 \mathrm{E}-8$ & 8.213 \\
Data by [41] & 0.217 & 951.92 & 1.342 & $1.71 \mathrm{E}-7$ & 8.211 \\
Data by [51] & 0.2108 & 145.083 & 1.1578 & $1.01 \mathrm{E}-8$ & 8.226 \\
Data by [38] & 0.21095 & 192.757 & 1.1482 & $8.6369 \mathrm{E}-9$ & 8.218985 \\
\hline
\end{tabular}

Solinc $120 \mathrm{~W}$ using approaches 1 - 4 of Table 3.

These data are summarized in Table 5 for $R_{s h}$ of Equation (27) that gives the smallest error for each approach. Approach 1 data and data from [52] have similar results while approaches 2 and 3 have different $R_{s h}$ values for the same $R_{s}=$ $0.233 \Omega$. However, approach 4 has $R_{s}=0.2395 \Omega$ that gives the least $\Delta P_{\text {mpp }}$ error and very large value of $R_{s h}=18565 \Omega$. Analytical approach reported by [41] provides satisfactory parameters that are closer to the values obtained using the four approaches.

The results obtained using analytical methods published by [38] [40] [41] [50] [51] [52] have been compared with the KC200GT parameters values in Table 4 and summarized in Table 6. The values of $R_{s}$ obtained using the four methods discussed in this work are consistent with their analysis within $\pm 0.02 \Omega$. All parameter values shown in Table 4 provide satisfactory results for output power within the error margin given by the manufacturer of $+10 \%$ or $-5 \%$. A typical way of testing the 5-parameter model is through $\mathrm{I}-\mathrm{V}$ and $\mathrm{P}-\mathrm{V}$ plots.

\section{I-V and P-V Characterization for Solinc $120 \mathrm{~W}$ and KC200GT Photovoltaic Modules Based on the Four Approaches at STC}

The values of simulated parameters listed in Table 5 \& Table 6 for Solinc $120 \mathrm{~W}$ and KC200GT, have been used to plot the I-V and P-V curves at standard test condition.

Figure 5 shows the current-voltage relationship for Solinc $120 \mathrm{~W}$, in which the zoomed parts illustrate the short circuit, maximum power and open circuit points for all the four approaches. The curves converge at maximum power point but vary significantly at the point of short circuit and at the point of open circuit. The second approach gives the best replica of these cardinal points. 
Figure 6 shows the power-voltage relationship for Solinc $120 \mathrm{~W}$ solar module, in which the zoomed sections show the areas surrounding the maximum power and the open circuit points. The zoomed sections show the differences between the four approaches, which is a reflection of the values of errors given in Table 4.

The current-voltage relationship for KC200GT is shown in Figure 7, in which the zoomed sections represent the short circuit, maximum power and open circuit points. The curves converge at maximum power point but vary greatly at the point of the short circuit and at the point of the open circuit. Again, the second method offers the best possible representation of these cardinal points.

Figure 8 displays the power-voltage relationship for KC200GT solar module, in which the zoomed parts represent the areas surrounding the maximum power and the open circuit points. The zoomed sections display the differences between the four methods, which is a representation of error values given in Table 5. According to the I-V and P-V plots of Figures 5-8, the four analytical approaches give satisfactory parameters values for a single diode model that matches the experimental data and manufacturer's profile.

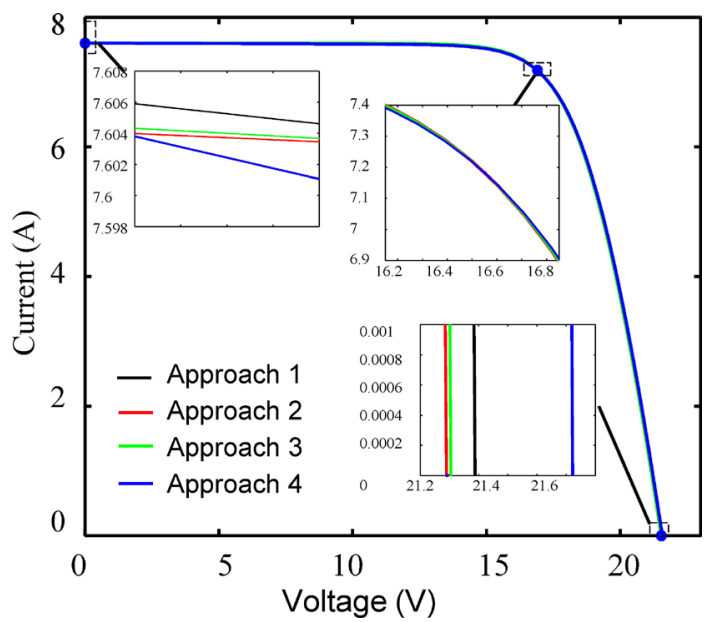

Figure 5. A graph of current versus voltage for Solinc $120 \mathrm{~W}$ at STC.

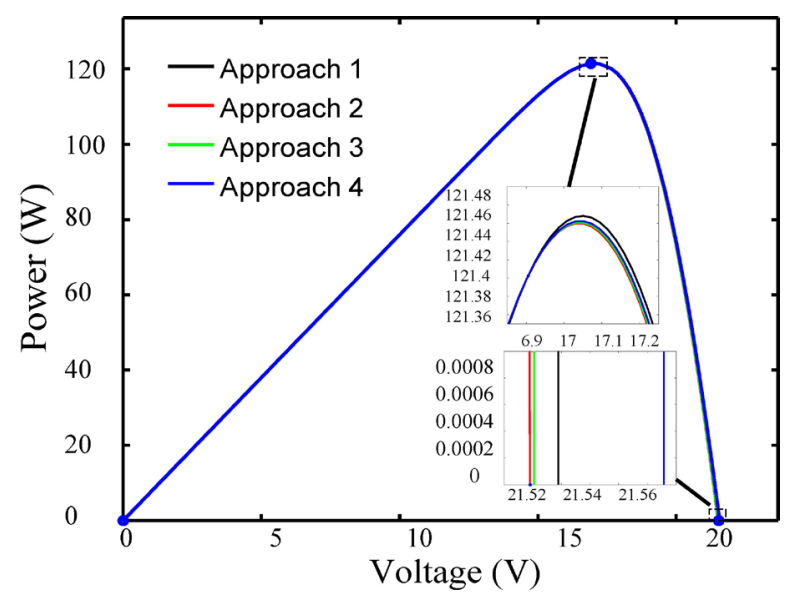

Figure 6. A graph of power versus s voltage for Solinc $120 \mathrm{~W}$ at STC. 


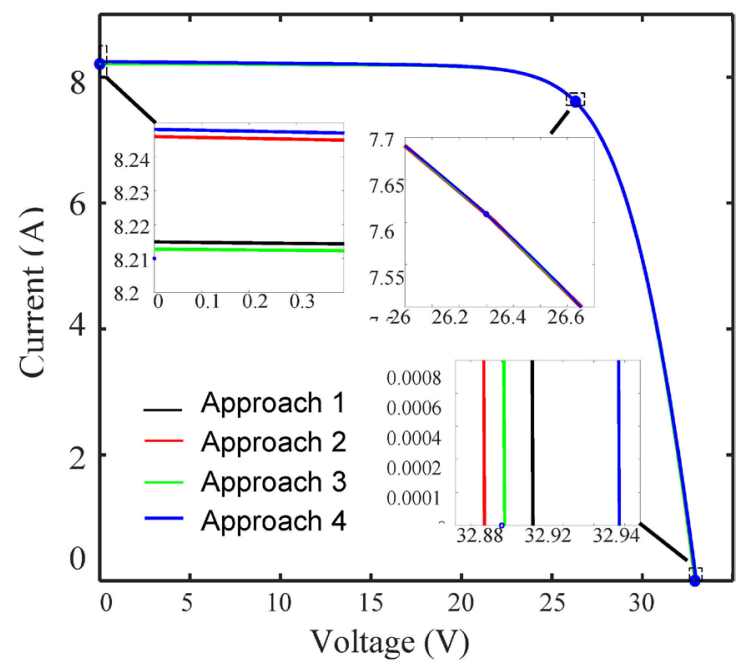

Figure 7. A graph of current versus s voltage for KC200GT at STC.

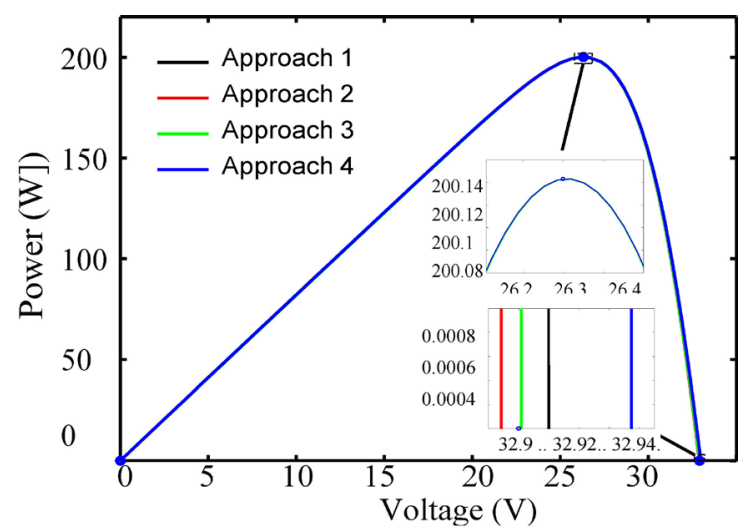

Figure 8. A graph of power versus voltage for KC200GT at STC.

\section{I-V and P-V Characterization at Ambient Temperature, NOCT and Actual Irradiance}

The effects of the actual solar irradiation $\left(s_{a}\right)$ and module's surface temperature $T$ on five-model parameters have been recently studied at open circuit, closed circuit and maximum power points [38] [51].

Starting with the cardinal points, the short circuit current can be determined using

$$
I_{s c}\left(s_{a}, T\right)=\frac{s_{a}}{s_{S T C}}\left[I_{s c}+K_{I_{s c}}\left(T-T_{S T C}\right)\right]
$$

where, $K_{I_{s c}}$ is the temperature coefficient of $I_{s c}$ in $\mathrm{A} /{ }^{\circ} \mathrm{C}$ that is usually provided in manufacturer's data sheet. The maximum power-point current can be determined using

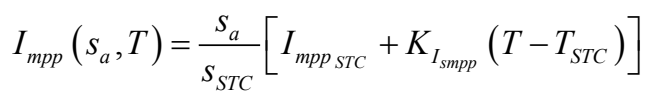

where, $K_{I_{m p p}}$ is the temperature coefficient of $I_{m p p}$ in A/ ${ }^{\circ} \mathrm{C}$. Unlike $K_{I_{s c}}$, the manufacturer's data sheet does not include $K_{I_{m p p}}$. This can be evaluated by 
simply applying the data at both STC and NOCT.

Manufacturers of solar modules with ISO/IEC International Standard provide, nominal operation cell temperature (NOCT) values at $800 \mathrm{~W} / \mathrm{m}^{2}$ at $20^{\circ} \mathrm{C}$ [55] [56]. This can be used to relate the module temperature $(\mathrm{T})$ with the actual irradiance and the air temperature $\left(T_{a}\right)$ using

$$
T=T_{a}+\frac{\left[T_{N O C T}-20\right] s_{a}}{800}
$$

For maximum power-point voltage a more robust analytical approach has been recently used by [38], in which

$$
V_{m p p}\left(s_{a}, T\right)=V_{m p p_{S T C}}+K_{v_{\text {mpp }}}\left(T-T_{S T C}\right)+\alpha_{v_{\text {mpp }}}\left(s_{a}-s_{S T C}\right)+\beta_{v_{\text {mpp }}}\left(s_{a}-s_{S T C}\right)^{2}
$$

where, $\alpha_{V_{m p p}}$ and $\beta_{V_{m p p}}$ are solar radiation coefficients at maximum-power point. Similarly, the short-circuit voltage can be evaluated as

$$
V_{o c}\left(s_{a}, T\right)=V_{o c_{S T C}}+K_{v_{o c}}\left(T-T_{S T C}\right)+\alpha_{V_{o c}}\left(s_{a}-s_{S T C}\right)+\beta_{V_{o c}}\left(s_{a}-s_{S T C}\right)^{2}
$$

where $\alpha_{V_{O c}}, \beta_{V_{o c}}$ are solar radiation coefficients at open circuit point.

Equations (51) and (52) are quadratic polynomials that require a careful extraction of the second-degree polynomial coefficients. In this paper, we have introduced a simpler approach for determining $V_{o c}\left(s_{a}, T\right)$ and $V_{m p p}\left(s_{a}, T\right)$ using

$$
V_{o c}\left(s_{a}, T\right)=n\left(s_{a}, T\right) N_{s} V_{t}(T)\left[\ln \left(I_{s c}\left(s_{a}, T\right)\right)-\ln \left(I_{o}\left(s_{a}, T\right)\right)\right]
$$

and,

$$
V_{m p p}\left(s_{a}, T\right)=V_{o c}\left(s_{a}, T\right)-n_{o} N_{s} V_{t}(T) \times\left[\ln \left(\frac{I_{s c}\left(s_{a}, T\right)}{I_{s c}\left(s_{a}, T\right)-I_{m p p}\left(s_{a}, T\right)}\right)\right]
$$

The saturation current dependence on module temperature can be achieved by rewriting Equation (20) as

$$
I_{o}\left(s_{a}, T\right)=I_{\text {OSTC }}\left[\frac{T}{T_{S T C}}\right]^{3} \exp \frac{-q E_{g}}{n\left(s_{a}, T\right) N_{s}}\left(\frac{1}{T_{S T C}}-\frac{1}{T}\right) .
$$

The temperature-dependent saturation current of Equation (55) can be compared with $I_{o}$ of Equation (56), in which Equation (14) has been written as

$$
I_{o}=\frac{I_{s c}\left(s_{a}, T\right)}{\exp \left(\frac{V_{o c}\left(s_{a}, T\right)}{n\left(s_{a}, T\right) N_{s} V_{t}(T)}\right)} .
$$

Finally, the $R_{s}$ and $R_{s h}$ pair dependency on irradiance and temperature have been evaluated using Equation (27), by replacing its $I_{p h}, I_{o}, I_{m p p}$ and $V_{m p p}$ with values extracted using Equations ((7), (56), (49) and (54)) respectively.

The Kyocera KC200GT high-performance multi-crystal photovoltaic module with IEC standard has been used to demonstrate the effects of irradiance and temperature on main parameters of a single diode model as shown in Table 7 \& Table 8. The datasheet module offers nominal operating cell temperature data at $47^{\circ} \mathrm{C}$ and $800 \mathrm{~W} / \mathrm{m}^{2}$ for the three cardinal points that have been used as starting 
Table 7. Simulated data and extracted model parameters values for KC200GT photovoltaic module at air temperature of $20^{\circ} \mathrm{C}$ and NOCT of $47^{\circ} \mathrm{C}$ and different irradiance levels.

\begin{tabular}{cccccc}
\hline Irradiance $\left(\mathrm{W} / \mathrm{m}^{2}\right)$ & 200 & 400 & 600 & 800 & 1000 \\
$I_{s c}(\mathrm{~A})$ & 1.653 & 3.306 & 4.959 & 6.612 & 8.28 \\
$I_{m p p}(\mathrm{~A})$ & 1.533 & 3.066 & 4.599 & 6.132 & 7.665 \\
$V_{m p p}(\mathrm{~V})$ & 20.134 & 21.518 & 22.327 & 22.901 & 23.412 \\
$V_{m p p}(\mathrm{~V})$ Ref. [38] method & 21.549 & 22.295 & 22.822 & 23.130 & 23.220 \\
$V_{o c}(\mathrm{~V})$ & 27.239 & 28.623 & 29.432 & 30.006 & 30.455 \\
$V_{o c}(\mathrm{~V})$ Ref. [38] method & 28.062 & 28.818 & 29.425 & 29.884 & 30.194 \\
$n$ & 1.1 & 1.12 & 1.28 & 1.32 & 1.34 \\
$I_{o} \times 10^{-6}(\mathrm{~A})$ & 998.90 & 11.728 & 98.249 & 1.5618 & 1.9613 \\
$I_{p h}(\mathrm{~A})$ & 1.6564 & 3.3082 & 4.9629 & 6.6164 & 8.2844 \\
$R_{s}(\Omega)$ & 1.742 & 0.802 & 0.452 & 0.313 & 0.242 \\
$R_{s h}(\Omega)$ & 1750.956 & 555.481 & 2864.877 & 2235.484 & 6896.84 \\
$P_{m p p}(\mathrm{~W})$ & 30.924 & 66.098 & 102.814 & 140.574 & 179.561 \\
$\Delta P_{m p p} \%$ & 0.1911 & 0.1879 & 0.1285 & 0.1037 & 0.0603 \\
\hline
\end{tabular}

conditions to evaluate other parameters at various irradiances. In Table 7, the simulated $I_{s c}\left(s_{a}, T\right), I_{m p p}\left(s_{a}, T\right), V_{m p p}\left(s_{a}, T\right)$ and $V_{o c}\left(s_{a}, T\right)$ data have been applied in approach 2 discussed in section 5.1 to extracted $I_{p h}\left(s_{a}, T\right), I_{o}\left(s_{a}, T\right), n\left(s_{a}, T\right) R_{s}$ $\left(s_{a}, T\right)$ and $R_{s h}\left(s_{a}, T\right)$ and plot I-V and P-V curves at various irradiances.

The values of $\alpha_{V_{m p p}}, \alpha_{V_{o c}}, \beta_{V_{m p p}}$ and $\beta_{V_{o c}}$ presented in the supplementary data published by [38], have been applied to determine $V_{m p p}$ and $V_{o c}$ of equations (51) and (52). The simulated values of $V_{o c}$ using Equation (53) and $V_{m p p}$ using Equation (54) for irradiances chosen at 200, 400, 600, 800 and $1000 \mathrm{~W} / \mathrm{m}^{2}$, have been compared with the values obtained based on the [38] method as shown in Table 7. The data obtained using the new approaches are consistent with data simulated using [38] method. Figure 9 \& Figure 10 illustrate the I-V and P-V curves at irradiances of 200, 400,600, 800 and $1000 \mathrm{~W} / \mathrm{m}^{2}$, and air temperature of $20^{\circ} \mathrm{C}$ and NOCT of $47^{\circ} \mathrm{C}$, while Figure 11 \& Figure 12 show I-V and $\mathrm{P}-\mathrm{V}$ curves at various temperatures.

\section{Conclusions}

In this report, we have considered photovoltaic systems operating at STC and various weather conditions and have presented two algorithms for extracting their five-model parameters based on a single-diode analogous circuit. The first algorithm plays an important role in deriving the unknown parameters to give a rough idea of their values that are used as preliminary data for the second algorithm based on Newton-Raphson numerical analysis method. This is a deviation from conventional methods, which assume initial arbitrary values.

In an attempt to establish the most comprehensive and simple procedure of arriving at the best five-model parameters, we categorized four approaches based 


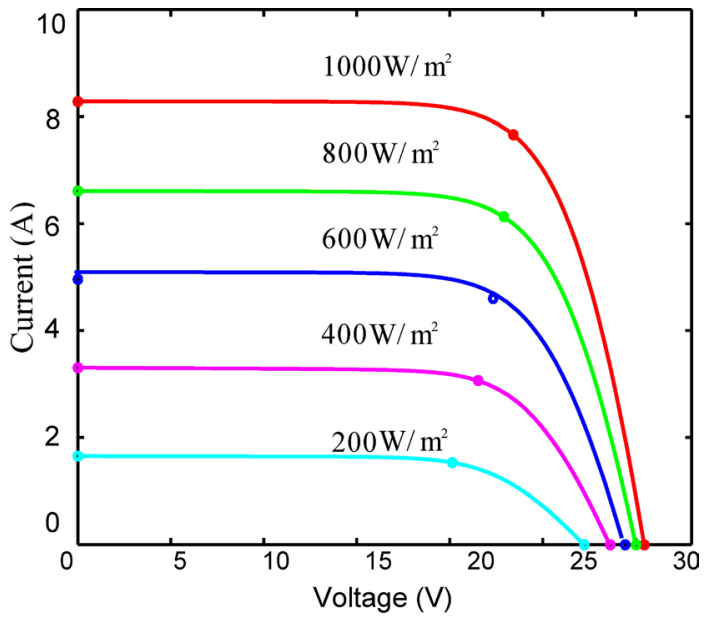

Figure 9. A graph of current versus voltage for KC200GT at air temperature of $20^{\circ} \mathrm{C}$ and NOCT of $47^{\circ} \mathrm{C}$ for various irradiances.

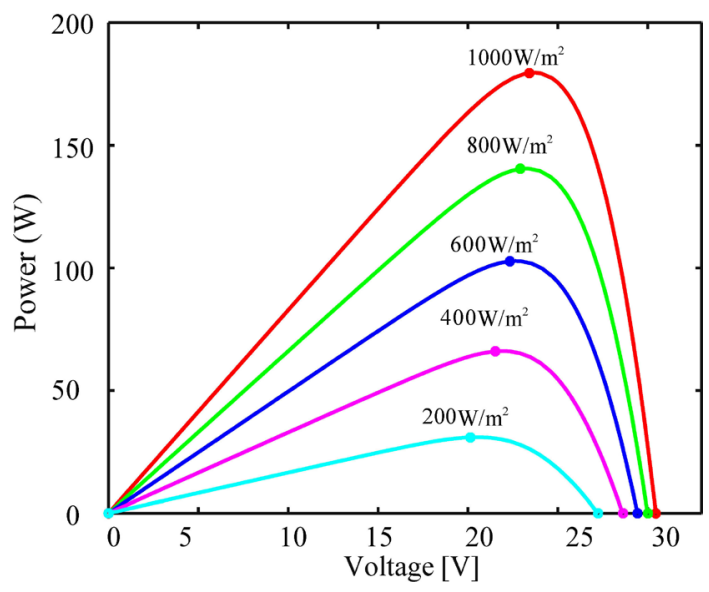

Figure 10. A graph of current versus voltage for KC200GT at air temperature of $20^{\circ} \mathrm{C}$ and NOCT of $47^{\circ} \mathrm{C}$ for various irradiances.

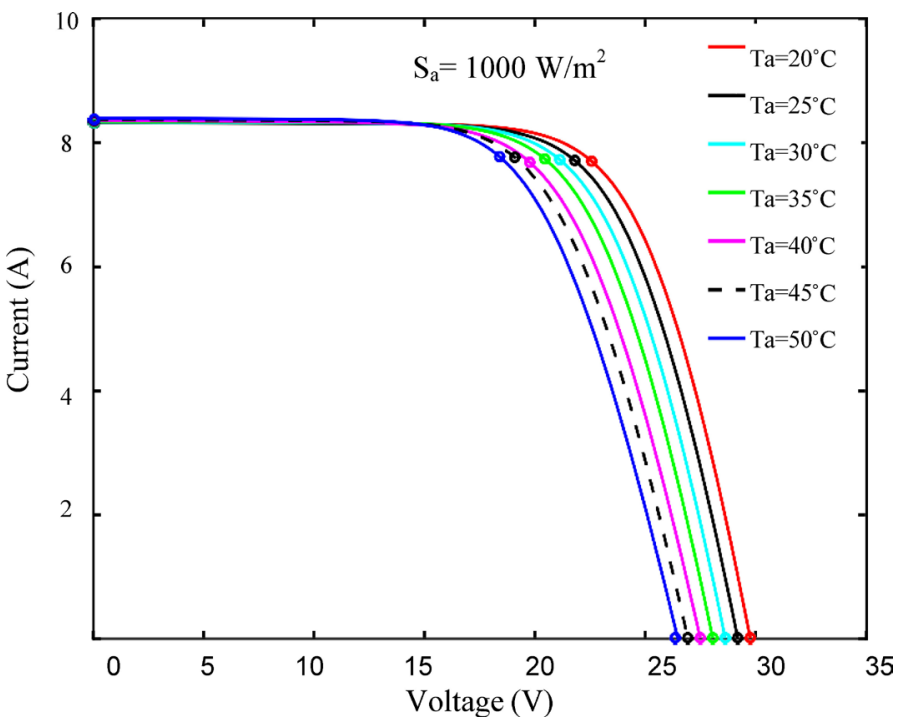

Figure 11. A graph of current versus voltage for KC200GT showing various temperatures curves at $1000 \mathrm{~W} / \mathrm{m}^{2}$. 
Table 8. Simulated data and extracted model parameters values for KC200GT photovoltaic module at arbitrary air and NOCT temperatures for $1000 \mathrm{~W} / \mathrm{m}^{2}$.

\begin{tabular}{|c|c|c|c|c|c|c|c|c|}
\hline \multicolumn{2}{|l|}{$\mathrm{T}_{\mathrm{a}}\left({ }^{\circ} \mathrm{C}\right)$} & 20 & 25 & 30 & 35 & 40 & 45 & 50 \\
\hline \multicolumn{2}{|c|}{$\operatorname{NOCT}\left({ }^{\circ} \mathrm{C}\right)$} & 53.75 & 58.75 & 63.75 & 68.75 & 73.75 & 78.75 & 83.75 \\
\hline \multicolumn{2}{|c|}{$T$ (Kelvin) } & 326.9 & 331.9 & 336.9 & 341.9 & 346.9 & 351.9 & 356.9 \\
\hline \multicolumn{2}{|l|}{$I_{s c}(\mathrm{~A})$} & 8.3014 & 8.2944 & 8.3069 & 8.3194 & 8.3319 & 8.3444 & 8.3569 \\
\hline \multicolumn{2}{|l|}{$I_{m p p}(\mathrm{~A})$} & 7.6819 & 7.6944 & 7.7069 & 7.7194 & 7.6650 & 7.7444 & 7.7569 \\
\hline \multicolumn{2}{|l|}{$V_{m p p}(\mathrm{~V})$} & 22.522 & 21.758 & 21.079 & 20.399 & 19.717 & 19.034 & 18.350 \\
\hline \multicolumn{2}{|c|}{$V_{m p p}(\mathrm{~V})$ Ref. [38] method } & 22.275 & 21.575 & 20.875 & 20.175 & 19.475 & 18.775 & 18.075 \\
\hline \multicolumn{2}{|l|}{$V_{o c}(\mathrm{~V})$} & 29.700 & 29.133 & 28.570 & 28.005 & 27.440 & 26.872 & 26.304 \\
\hline \multicolumn{2}{|c|}{$V_{o c}(\mathrm{~V})$ Ref. [38] method } & 29.364 & 28.749 & 28.134 & 27.519 & 26.904 & 26.289 & 25.674 \\
\hline \multicolumn{2}{|l|}{$n$} & 1.16 & 1.14 & 1.13 & 1.124 & 1.1 & 1.06 & 1.012 \\
\hline \multicolumn{2}{|c|}{$I_{o} \times 10^{-6}(\mathrm{~A})$} & 40.682 & 54.031 & 82.299 & 1.3145 & 1.6203 & 1.577 & 1.2491 \\
\hline \multicolumn{2}{|l|}{$I_{p h}(\mathrm{~A})$} & 8.3120 & 8.3062 & 8.3199 & 8.334 & 8.3546 & 8.3642 & 8.3812 \\
\hline \multicolumn{2}{|l|}{$R_{s}(\Omega)$} & 0.332 & 0.352 & 0.363 & 0.371 & 0.412 & 0.418 & 0.468 \\
\hline \multicolumn{2}{|l|}{$R_{s h}(\Omega)$} & 913.865 & 928.483 & 925.197 & 831.949 & 437.605 & 726.471 & 814.787 \\
\hline \multicolumn{2}{|c|}{$P_{m p p}(\mathrm{~W})$} & 173.043 & 167.596 & 162.742 & 157.875 & 151.425 & 148.048 & 143.036 \\
\hline \multicolumn{2}{|l|}{$\Delta P_{m p p} \%$} & 0.0191 & 0.1108 & 0.1787 & 0.2601 & 0.1940 & 0.4339 & 0.4901 \\
\hline \multirow[t]{2}{*}{$\sum_{0}^{\sum_{0}^{0}} 100$} & $\begin{array}{r}-\mathrm{Ta}=2 \\
-\mathrm{Ta}=2 \\
-\mathrm{Ta}=3 \\
-\mathrm{Ta}=3 \\
-\mathrm{Ta}=4 \\
-{ }^{\mathrm{Ta}}=4 \\
-\mathrm{Ta}=5\end{array}$ & $\begin{array}{l}5^{\circ} \mathrm{C} \\
0^{\circ} \mathrm{C} \\
5^{\circ} \mathrm{C} \\
0^{\circ} \mathrm{C} \\
5^{\circ} \mathrm{C} \\
0^{\circ} \mathrm{C}\end{array}$ & $a=10$ & & & & & \\
\hline & 0 & 5 & 10 & $\begin{array}{l}15 \\
\text { Voltage }\end{array}$ & $\begin{array}{l}20 \\
\text { V) }\end{array}$ & 25 & 30 & \\
\hline
\end{tabular}

Figure 12. A graph of power versus voltage for KC200GT showing various temperatures curves at $1000 \mathrm{~W} / \mathrm{m}^{2}$.

of saturation-current relationships at the cardinal points of I-V plot. We considered the effect of shunt and series resistance on the saturation current at each key cardinal point or combination of two points, and found that dependence on the actual resistance induces a slight deviation of the saturation current as opposed to extreme resistance. When applied to the Newton-Raphson numerical analysis method, all four approaches provided satisfactory output current and 
voltage values that match the experimental data or data presented in manufacturer's datasheet.

Beginning with the numerical values of the five-model parameters at STC, we simulated the five-model parameters at various irradiances and temperatures. We have presented new approaches to obtaining the $V_{o c}$ and $V_{m p p}$ at various irradiances and temperatures.

\section{Acknowledgements}

The authors would like to thank the Department of Physics and the Board of Graduate School; University of Nairobi (Kenya) for providing all the facilities and financial support respectively for this research.

\section{Conflicts of Interest}

The authors declare no conflicts of interest regarding the publication of this paper.

\section{References}

[1] Bórawski, P., Yashchenko, T., Sviderskyi, A. and Dunn, J.W. (2019) Development of Renewable Energy Market in the EU with Particular Regard to Solar Energy. Conference Proceedings Determinants of Regional Development, Pila, 12-13 April 2018, 43-55.

[2] Albini, A. and Rajnai, Z. (2019) Modeling General Energy Balance of Systems. Procedia Manufacturing, 32, 374-379. https://doi.org/10.1016/j.promfg.2019.02.228

[3] Kabir, E., Kumar, P., Kumar, S., Adelodun, A.A. and Kim, K.H. (2018) Solar Energy: Potential and Future Prospects. Renewable and Sustainable Energy Reviews, 82, 894-900. https://doi.org/10.1016/j.rser.2017.09.094

[4] Kannan, N. and Vakeesan, D. (2016) Solar Energy for Future World: A Review. Renewable and Sustainable Energy Reviews, 62, 1092-1105.

https://doi.org/10.1016/j.rser.2016.05.022

[5] Ishaque, K. and Salam, Z. (2013) A Review of Maximum Power Point Tracking Techniques of PV System for Uniform Insolation and Partial Shading Condition. Renewable and Sustainable Energy Reviews, 19, 475-488. https://doi.org/10.1016/j.rser.2012.11.032

[6] Salas, V., Olias, E., Barrado, A. and Lazaro, A. (2006) Review of the Maximum Power Point Tracking Algorithms for Stand-Alone Photovoltaic Systems. Solar Energy Materials and Solar Cells, 90, 1555-1578. https://doi.org/10.1016/j.solmat.2005.10.023

[7] Belhachat, F. and Larbes, C. (2018) A Review of Global Maximum Power Point Tracking Techniques of Photovoltaic System under Partial Shading Conditions. Renewable and Sustainable Energy Reviews, 92, 513-553. https://doi.org/10.1016/j.rser.2018.04.094

[8] Nadia, A.R., Isa, N.A.M. and Desa, M.K.M. (2018) Advances in Solar Photovoltaic Tracking Systems: A Review. Renewable and Sustainable Energy Reviews, 82, 2548-2569. https://doi.org/10.1016/j.rser.2017.09.077

[9] Hafez, A.Z., Yousef, A.M. and Harag, N.M. (2018) Solar Tracking Systems: Technologies and Trackers Drive Types: A Review. Renewable and Sustainable Energy 
Reviews, 91, 754-782. https://doi.org/10.1016/j.rser.2018.03.094

[10] Jiang, L.L., Srivatsan, R. and Maskell, D.L. (2018) Computational Intelligence Techniques for Maximum Power Point Tracking in PV Systems: A Review. Renewable and Sustainable Energy Reviews, 85, 14-45.

https://doi.org/10.1016/j.rser.2018.01.006

[11] Boukebbous, S.E. and Kerdoun, D. (2015) Study, Modeling and Simulation of Photovoltaic Panels under Uniform and Non-Uniform Illumination Conditions. Revue des Energies Renouvelables, 18, 257-268.

[12] Kennerud, K.L. (1969) Analysis of Performance Degradation in CdS Solar Cells. IEEE Transactions on Aerospace and Electronic Systems, 6, 912-917. https://doi.org/10.1109/TAES.1969.309966

[13] Otterbein, R.T., Evans, D.L. and Facinelli, W.A. (1978) A Modified Single Diode Model for High Illumination Solar Cells for Simulation Work. 13th Photovoltaic Specialists Conference, Washington DC, 5-8 June 1978, 1074-1079.

[14] Charles, J.P., Abdelkrim, M., Muoy, Y.H. and Mialhe, P. (1981) A Practical Method of Analysis of the Current-Voltage Characteristics of Solar Cells. Solar Cells, 4, 169-178. https://doi.org/10.1016/0379-6787(81)90067-3

[15] Diantoro, M., Suprayogi, T., Hidayat, A., Taufiq, A., Fuad, A. and Suryana, R. (2018) Shockley's Equation Fit Analyses for Solar Cell Parameters from I-V Curves. International Journal of Photoenergy, 2018, Article ID: 9214820. https://doi.org/10.1155/2018/9214820

[16] Saha, C., Agbu, N., Jinks, R. and Huda, M.N. (2018) Review Article of the Solar PV Parameters Estimation Using Evolutionary Algorithms. MOJ Solar and Photoenergy Systems, 2, 66-78.

[17] Hachana, O., Hemsas, K.E., Tina, G.M. and Ventura, C. (2013) Comparison of Different Metaheuristic Algorithms for Parameter Identification of Photovoltaic Cell/Module. Journal of Renewable and Sustainable Energy, 5, Article ID: 053122. https://doi.org/10.1063/1.4822054

[18] Tamrakar, R. and Gupta, A. (2015) A Review: Extraction of Solar Cell Modelling Parameters. International Journal of Innovative Research in Electrical, Electronics, Instrumentation and Control Engineering, 3, 55-60. https://doi.org/10.17148/IJIREEICE.2015.3111

[19] Franco, R.A.P. and Vieira, F.H.T. (2018) Analytical Method for Extraction of the Single-Diode Model Parameters for Photovoltaic Panels from Datasheet Data. Electronics Letters, 54, 519-521. https://doi.org/10.1049/el.2018.0402

[20] Abbassi, R., Abbassi, A., Jemli, M. and Chebbi, S. (2018) Identification of Unknown Parameters of Solar Cell Models: A Comprehensive Overview of Available Approaches. Renewable and Sustainable Energy Reviews, 90, 453-474.

https://doi.org/10.1016/j.rser.2018.03.011

[21] Ghani, F., Duke, M. and Carson, J. (2013) Numerical Calculation of Series and Shunt Resistances and Diode Quality Factor of a Photovoltaic Cell Using the Lambert W-Function. Solar Energy, 91, 422-431. https://doi.org/10.1016/j.solener.2012.09.005

[22] Batzelis, E.I. and Papathanassiou, S.A. (2015) A Method for the Analytical Extraction of the Single-Diode PV Model Parameters. IEEE Transactions on Sustainable Energy, 7, 504-512. https://doi.org/10.1109/TSTE.2015.2503435

[23] Ibrahim, H. and Anani, N. (2017) Evaluation of Analytical Methods for Parameter Extraction of PV Modules. Energy Procedia, 134, 69-78. https://doi.org/10.1016/j.egypro.2017.09.601 
[24] Mohapatra, A., Nayak, B. and Mohanty, K.B. (2017) Parameter Extraction of PV Module Using NLS Algorithm with Experimental Validation. International Journal of Electrical and Computer Engineering, 7, 2392. https://doi.org/10.11591/ijece.v7i5.pp2392-2400

[25] Mahmoud, Y.A., Xiao, W. and Zeineldin, H.H. (2012) A Parameterization Approach for Enhancing PV Model Accuracy. IEEE Transactions on Industrial Electronics, 60, 5708-5716. https://doi.org/10.1109/TIE.2012.2230606

[26] Huang, P.H. and Xiao, W., Peng, J.C.H. and Kirtley, J.L. (2015) Comprehensive Parameterization of Solar Cell: Improved Accuracy with Simulation Efficiency. IEEE Transactions on Industrial Electronics, 63, 1549-1560. https://doi.org/10.1109/TIE.2015.2498139

[27] Sera, D., Teodorescu, R. and Rodriguez, P. (2007) PV Panel Model Based on Datasheet Values. 2007 IEEE International Symposium on Industrial Electronics, 4-7 June 2007, 2392-2396. https://doi.org/10.1109/ISIE.2007.4374981

[28] Yahfdhou, A., Mahmoud, A.K. and Youm, I. (2016) Evaluation and Determination of Seven and Five Parameters of a Photovoltaic Generator by an Iterative Method.

[29] Banwell, T.C. and Jayakumar, A. (2000) Exact Analytical Solution for Current Flow through Diode with Series Resistance. Electronics Letters, 36, 291-292. https://doi.org/10.1049/el:20000301

[30] Li, Y., Huang, W., Huang, H., Hewitt, C., Chen, Y., Fang, G. and Carroll, D.L. (2013) Evaluation of Methods to Extract Parameters from Current-Voltage Characteristics of Solar Cells. Solar Energy, 90, 51-57. https://doi.org/10.1016/j.solener.2012.12.005

[31] Zhang, Z.Z., Cheng, X.F. and Liu, J.L. (2013) An Improvement Method for Extracting Five Parameters of a Solar Cell Based on Lambert W-Function with the Current-Voltage Data. In Applied Mechanics and Materials, 291, 38-42. https://doi.org/10.4028/www.scientific.net/AMM.291-294.38

[32] Cubas, J., Pindado, S. and De Manuel, C. (2014) Explicit Expressions for Solar Panel Equivalent Circuit Parameters Based on Analytical Formulation and the Lambert W-Function. Energies, 7, 4098-4115. https://doi.org/10.3390/en7074098

[33] Nassar-Eddine, I., Obbadi, A., Errami, Y. and Agunaou, M. (2016) Parameter Estimation of Photovoltaic Modules Using Iterative Method and the Lambert W Function: A Comparative Study. Energy Conversion and Management, 119, 37-48. https://doi.org/10.1016/j.enconman.2016.04.030

[34] Park, J.Y. and Choi, S.J. (2015) A Novel Datasheet-Based Parameter Extraction Method for a Single-Diode Photovoltaic Array Model. Solar Energy, 122, 1235-1244. https://doi.org/10.1016/j.solener.2015.11.001

[35] Bonkoungou, D., Koalaga, Z., Njomo, D. and Zougmore, F. (2015) An Improved Numerical Approach for Photovoltaic Module Parameters Acquisition Based on Single-Diode Model. International Journal of Current Engineering and Technology, 5, 3735-3742.

[36] Ayodele, T.R., Ogunjuyigbe, A.S.O. and Ekoh, E.E. (2016) Evaluation of Numerical Algorithms Used in Extracting the Parameters of a Single-Diode Photovoltaic Model. Sustainable Energy Technologies and Assessments, 13, 51-59. https://doi.org/10.1016/j.seta.2015.11.003

[37] Shockley, W. (1949) The Theory of p-n Junctions in Semiconductors and p-n Junction Transistors. Bell System Technical Journal, 28, 435-489. https://doi.org/10.1002/j.1538-7305.1949.tb03645.x

[38] Zaimi, M., El Achouby, H., Ibral, A. and Assaid, E.M. (2019) Determining Com- 
bined Effects of Solar Radiation and Panel Junction Temperature on All Model-Parameters to Forecast Peak Power and Photovoltaic Yield of Solar Panel under Non-Standard Conditions. Solar Energy, 191, 341-359.

https://doi.org/10.1016/j.solener.2019.09.007

[39] Shen, W., Ding, Y., Choo, F.H., Wang, P., Loh, P.C. and Tan, K.K. (2009) Mathematical Model of a Solar Module for Energy Yield Simulation in Photovoltaic Systems. 2009 International Conference on Power Electronics and Drive Systems, Taipei, 2-5 November 2009, 336-341. https://doi.org/10.1109/PEDS.2009.5385657

[40] Hejri, M., Mokhtari, H., Azizian, M.R. and Söder, L. (2016) An Analytical-Numerical Approach for Parameter Determination of a Five-Parameter Single-Diode Model of Photovoltaic Cells and Modules. International Journal of Sustainable Energy, 35, 396-410. https://doi.org/10.1080/14786451.2013.863886

[41] Atay, B.K. and Eminoğlu, U. (2019) A New Approach for Parameter Estimation of the Single-Diode Model for Photovoltaic Cells/Modules. Turkish Journal of Electrical Engineering \& Computer Sciences, 27, 3026-3039. https://doi.org/10.3906/elk-1805-161

[42] Rauschenbusch, H.S. (1971) Electrical Output of Shadowed Solar Arrays. IEEE Transactions on Electron Devices, 18, 483-490. https://doi.org/10.1109/T-ED.1971.17231

[43] Castaner, L. and Silvestre, S. (2002) Modelling Photovoltaic Systems Using PSpice. John Wiley and Sons, Hoboken. https://doi.org/10.1002/0470855541

[44] Neville, R.C. (1995) Solar Energy Conversion: The Solar Cell. Elsevier, Amsterdam.

[45] Sze, S.M. and Ng, K.K. (2006) Physics of Semiconductor Devices. John Wiley and sons, Hoboken. https://doi.org/10.1002/0470068329

[46] Ataboev, O.K., Kabulov, R.R., Matchanov, N.A. and Egamov, S.R. (2019) Influence of Temperature on the Output Parameters of a Photovoltaic Module Based on Amorphous Hydrogenated Silicon. Applied Solar Energy, 55, 159-167. https://doi.org/10.3103/S0003701X19030022

[47] Chenni, R., Makhlouf, M., Kerbache, T. and Bouzid, A. (2007) A Detailed Modeling Method for Photovoltaic Cells. Energy, 32, 1724-1730. https://doi.org/10.1016/j.energy.2006.12.006

[48] Ndegwa, R., Simiyu, J., Ayieta, E. and Odero, N. (2020) A Fast and Accurate Analytical Method for Parameter Determination of a Photovoltaic System Based on Manufacturer's Data. Journal of Renewable Energy, 2020, Article ID: 7580279. https://doi.org/10.1155/2020/7580279

[49] Phang, J.C.H., Chan, D.S.H. and Phillips, J.R. (1984) Accurate Analytical Method for the Extraction of Solar Cell Model Parameters. Electronics Letters, 20, 406-408. https://doi.org/10.1049/el:19840281

[50] Cubas, J., Pindado, S. and Farrahi, A. (2013) New Method for Analytical Photovoltaic Parameter Extraction. 2013 International Conference on Renewable Energy Research and Applications, Madrid, 20-23 October 2013, 873-877. https://doi.org/10.1109/ICRERA.2013.6749874

[51] El Achouby, H., Zaimi, M., Ibral, A. and Assaid, E.M. (2018) New Analytical Approach for Modelling Effects of Temperature and Irradiance on Physical Parameters of Photovoltaic Solar Module. Energy Conversion and Management, 177, 258-271. https://doi.org/10.1016/j.enconman.2018.09.054

[52] Villalva, M.G., Gazoli, J.R. and Ruppert Filho, E. (2009) Comprehensive Approach to Modeling and Simulation of Photovoltaic Arrays. IEEE Transactions on Power Electronics, 24, 1198-1208. https://doi.org/10.1109/TPEL.2009.2013862 
[53] Carrero, C., Rodriguez, J., Ramírez, D. and Platero, C. (2010) Simple Estimation of PV Modules Loss Resistances for Low Error Modelling. Renewable Energy, 35, 1103-1108. https://doi.org/10.1016/j.renene.2009.10.025

[54] Reis, L.R.D., Camacho, J.R. and Novacki, D.F. (2017) The Newton Raphson Method in the Extraction of Parameters of PV Modules. Proceedings of the International Conference on Renewable Energies and Power Quality, Malaga, 4-6 April 2017, 634-639.

[55] Markvart, T., McEvoy, A. and Castaner, L. (2003) Practical Handbook of Photovoltaic: Fundamentals and Applications. Elsevier, Amsterdam.

[56] Schwingshackl, C., Petitta, M., Wagner, J.E., Belluardo, G., Moser, D., Castelli, M., Zebisch, M. and Tetzlaff, A. (2013) Wind Effect on PV Module Temperature: Analysis of Different Techniques for an Accurate Estimation. Energy Procedia, 40, 77-86. https://doi.org/10.1016/j.egypro.2013.08.010 